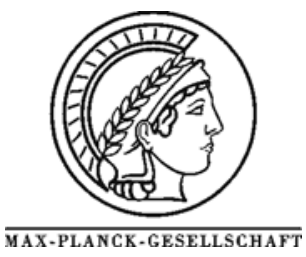

\title{
Steam reforming of methanol over copper-containing catalysts: influence of support material on microkinetics
}

\author{
B. Frank ${ }^{\mathrm{a}}$, F.C. Jentoft ${ }^{\mathrm{b}}$, H. Soerijanto ${ }^{\mathrm{a}, \mathrm{b}}$, J. Kröhnert ${ }^{\mathrm{b}}$, R. Schlögl ${ }^{\mathrm{b}}$, R. Schomäcker ${ }^{\mathrm{a}, *}$ \\ ${ }^{a}$ Institute of Chemistry, TU Berlin, Secr. TC-8, Straße des 17. Juni 124, 10623 Berlin, Germany \\ ${ }^{b}$ Department of Inorganic Chemistry, Fritz-Haber-Institute of the MPG, Faradayweg 4-6, 14195 Berlin, Germany \\ *Corresponding author: e-mail schomaecker@tu-berlin.de, Phone +49 30314 24973, Fax +49 3031479552
}

Received 16 October 2006; revised 28 November 2006; accepted 28 November 2006

\begin{abstract}
Steam reforming of methanol (SRM) was investigated over copper-containing catalysts supported on four different oxides and mixed oxides: $\mathrm{Cu} / \mathrm{ZnO} / \mathrm{Al}_{2} \mathrm{O}_{3}, \mathrm{Cu} / \mathrm{ZrO}_{2} / \mathrm{CeO}_{2}, \mathrm{Cu} / \mathrm{SiO}_{2}$ and $\mathrm{Cu} / \mathrm{Cr}_{2} \mathrm{O}_{3} / \mathrm{Fe}_{2} \mathrm{O}_{3}$. After observing slight differences in the way of catalyst aging and experimental exclusion of mass transport limitation effects, a detailed kinetic study was carried out at $493 \mathrm{~K}$. The dependence of the reaction rate on the molar ratio of methanol and water was determined as well as the influence of addition of inert nitrogen and the main reaction products hydrogen and carbon dioxide to the reactant mixture. Although there were remarkable differences in the catalytic activity of the samples, the main mechanistic steps reflected in the rate law appeared to be similar for all catalysts. The reaction rate is mainly determined by the methanol partial pressure, whereas water is not involved in the rate determining step, except over $\mathrm{Cu} / \mathrm{Cr}_{2} \mathrm{O}_{3} / \mathrm{Fe}_{2} \mathrm{O}_{3}$, where several differences in the chemistry were observed. Hydrogen and carbon dioxide were found to inhibit the reaction. These results were confirmed by a DRIFTS study at $493 \mathrm{~K}$ using an equimolar reactant mixture and an excess of 4:1 of water and methanol, respectively. The same surface species could be identified on each catalyst but neither kinetic modelling nor the DRIFTS spectra could give a clear answer if the reaction pathway occurs via a dioxomethylene or a methyl formate species as intermediate. Similar activation energies of SRM confirm the assumption, that the surface chemistry of SRM over copper-based systems is independent of the catalyst support material.
\end{abstract}

Keywords: Steam reforming of methanol, Copper catalyst, $\mathrm{Cu} / \mathrm{ZnO} / \mathrm{Al}_{2} \mathrm{O}_{3}, \mathrm{Cu} / \mathrm{ZrO}_{2} / \mathrm{CeO}_{2}, \mathrm{Cu} / \mathrm{SiO}_{2}, \mathrm{Cu} / \mathrm{Cr}_{2} \mathrm{O}_{3} / \mathrm{Fe}_{2} \mathrm{O}_{3}$, Microkinetics, Mechanistic model, DRIFTS, Surface species

\section{Introduction}

For environmental reasons, the replacement of combustion engines by fuel cells and electrical motors in cars is of general interest especially in traffic-polluted metropolitan areas. The production of electricity in a $\mathrm{H}_{2}-\mathrm{O}_{2}$ fuel cell is regarded as a clean process with a high energy efficiency delivering only water as exhaust material. The major problem is the handling, storage and transport of hydrogen, since liquefaction is very expensive and pressure tanks are suitable only for large vehicles, e.g. buses, due to their volume and weight to ensure the appropriate safety. A very promising alternative is the physisorption on carbon nanotubes [1], but this technology is still too expensive and not yet ready for technical application. So very early the onboard production of hydrogen from liquid hydrogen-rich hydrocarbons moved in the focus of research. Methanol was found to be a suitable candidate for on-board reforming due to a low process temperature and a high ratio of hydrogen to carbon [2]. It can be produced from fossil sources like natural gas, oil or coal or from renewable sources like biomass [3]. Furthermore the existing infrastructure of gas stations can also be used for methanol supply without extensive investments. A perspective for the application of methanol beyond fossil fuels is given by Olah [4].

The steam reforming of methanol (SRM) is potentially a good process for on-board production of hydrogen for mobile fuel cells yielding the maximum amount of hydrogen. Copper based catalysts have been identified as outstandingly effective for the SRM and therefore are subject of intensive research. The formal reaction network of SRM over copper based catalysts mainly consists of three reactions $[5,6]$. Steam reforming of methanol (Eq. 1) is an 
endothermic reaction which is as good as irreversible at temperatures above $200{ }^{\circ} \mathrm{C}$ and ambient pressure.

$\mathrm{CH}_{3} \mathrm{OH}(\mathrm{g})+\mathrm{H}_{2} \mathrm{O}(\mathrm{g}) \rightarrow 3 \mathrm{H}_{2}+\mathrm{CO}_{2}$,

$\Delta H^{0}=49.6 \mathrm{~kJ} \mathrm{~mol}^{-1}$

Since this reaction is endothermic, the reactor needs to be heated. This is usually done by catalytic methanol combustion [7]. A side reaction of less importance is the decomposition of methanol (MD, Eq. 2), also endothermic and nearly irreversible at temperatures above $200{ }^{\circ} \mathrm{C}$ and ambient pressure.

$\mathrm{CH}_{3} \mathrm{OH}(\mathrm{g}) \rightarrow 2 \mathrm{H}_{2}+\mathrm{CO}$,

$\Delta H^{0}=90.6 \mathrm{~kJ} \mathrm{~mol}^{-1}$

The reaction products of SRM suffer the consecutive endothermic reverse water-gas shift reaction (rWGS, Eq. 3), which is also known to be catalyzed by copper-based catalysts.

$\mathrm{H}_{2}+\mathrm{CO}_{2} \leftrightarrow \mathrm{H}_{2} \mathrm{O}(\mathrm{g})+\mathrm{CO}$,

$\Delta H^{0}=41.1 \mathrm{~kJ} \mathrm{~mol}^{-1}$

Although this reaction is thermodynamically strongly disfavoured in the typical temperature range of SRM and due to the presence of water in the reactant mixture, it becomes important as it was found to be the main reaction pathway for carbon monoxide formation [8]. The reduction of carbon monoxide, due to its poisoning effect on fuel cell electrodes, is an aim of new catalyst development with higher selectivity for SRM. Pt-based anodes are being deactivated by carbon monoxide in concentrations higher than $20 \mathrm{ppm}$. Alternative routes, adding oxygen to the feed (combined reforming of methanol) or using a molar excess of water, lower the carbon monoxide concentration but still not sufficiently for the direct use of the product gas mixture in a fuel cell. Up to now, carbon monoxide needs to be eliminated in an expensive clean-up unit, where carbon monoxide is selectively oxidized. Further by-products reported by several research groups are methane, formaldehyde, dimethyl ether and methyl formate as trace components, respectively.

Concerning the reaction mechanism of SRM a detailed model has been proposed by Peppley et al. [9] for a $\mathrm{Cu} / \mathrm{ZnO} / \mathrm{Al}_{2} \mathrm{O}_{3}$ catalyst. Mainly based on the extensive investigations on methanol synthesis the authors developed expressions for the reaction rates of steam reforming of methanol (Eq. 4), methanol decomposition and the watergas shift reaction. The rate expressions included surface

$$
\begin{aligned}
r_{R}= & \left(k _ { R } R _ { \mathrm { CH } _ { 3 } \mathrm { O } ^ { ( 1 ) } } ^ { * } \left(p_{\mathrm{CH}_{3} \mathrm{OH}} / p_{\mathrm{H}_{2}}^{1 / 2}\right.\right. \\
& \times\left(1-\left(p_{\mathrm{H}_{2}}^{3} p_{\mathrm{CO}_{2}} / k_{R} p_{\mathrm{CH}_{3} \mathrm{OH}} p_{\mathrm{H}_{2} \mathrm{O}}\right)\right) C_{S_{1}}^{T} C_{S_{1_{a}}}^{T} \\
& /\left(\left(1+K_{\mathrm{CH}_{3} \mathrm{O}^{(1)}}^{*}\left(p_{\mathrm{CH}_{3} \mathrm{OH}} / p_{\mathrm{H}_{2}}^{1 / 2}\right)\right.\right. \\
& +K_{\mathrm{HCOO}^{(1)}}^{*} p_{\mathrm{CO}_{2}} p_{\mathrm{H}_{2}}^{1 / 2}+K_{\mathrm{OH}^{(1)}}^{*}\left(p_{\mathrm{H}_{2} \mathrm{O}} / p_{\mathrm{H}_{2}}^{1 / 2}\right. \\
& \left.+K_{\mathrm{CO}_{2}^{(1)}}^{*} p_{\mathrm{CO}_{2}}\right)\left(1+K_{H_{(1 a)}}^{1 / 2} p_{\mathrm{H}_{2}}^{1 / 2}\right.
\end{aligned}
$$

species and intermediates that could be identified by diffuse reflectance infrared Fourier transform spectroscopy (DRIFTS); and for SRM the dehydrogenation of surface methoxy groups was identified as rate determining step (RDS).
Among several rate expressions, assembled by Lee et al. [10], this one was used directly or slightly modified in many other studies [11-14], in most cases in excellent agreement with the experimental data.

However, Peppley's comprehensive model gives no answer as to whether the reaction pathway occurs via methyl formate or dioxomethylene as intermediate. Although the methyl formate route was predicted based on the results of Jiang et al. [15], the corresponding adsorption term was deleted in the rate expression, since methyl formate was not detectable in Peppley's DRIFTS experiments. Indeed, exactly the same rate expression would be obtained assuming dioxomethylene as intermediate and deleting its adsorption term. Since only a few research groups ever detected methyl formate as trace by-product [16-18], and mostly in case of high methanol surplus, this step of the reaction pathway is still unclear. Takezawa, Takahashi et al. $[19,20]$ proposed a second reaction pathway via dioxomethylene by nucleophilic addition of surface hydroxyls to adsorbed formaldehyde for a $\mathrm{Cu} / \mathrm{SiO}_{2}$ catalyst. This attack occurs competitively to that of methoxy groups (Fig. 1) which can explain the formation of methyl formate observed only at high $\mathrm{MeOH} / \mathrm{H}_{2} \mathrm{O}$ ratios.

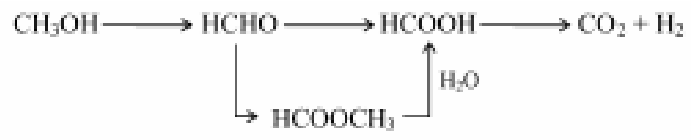

Figure 1: Reaction pathways of steam reforming of methanol over $\mathrm{Cu} / \mathrm{SiO}_{2}$ catalysts proposed by Takahashi et al. [20].

A further assumption by Peppley is the existence of two different kinds of active sites, one for oxygenate adsorption and one for hydrogen adsorption, based on a review by Skrzypek et al. [21]. Since most of the other kinetic models found in the literature are based on a single active site, notable differences in the dependency of the reaction rate from the hydrogen partial pressure should be predicted from the rate laws as discussed by Lee et al. [10]. Not taken into account in any model for SRM was the effect of hydrogen spillover. The existence of this elementary reaction step, although not rate determining, was reported and proved for methanol synthesis [22,23]. Hydrogen adsorbs dissociatively on the copper surface, which thereby provides a source of atomic hydrogen for methanol synthesis over oxidic phases. A possible relevancy of this process in SRM was mentioned $[9,24]$.

Up to now only a few studies on surface species detected by DRIFTS during SRM have been published. One spectrum of a $\mathrm{Cu} / \mathrm{ZnO} / \mathrm{Al}_{2} \mathrm{O}_{3}$ catalyst is given by Peppley et al. [9] and another one for a $\mathrm{CuO} / \mathrm{ZnO} / \mathrm{ZrO}_{2} / \mathrm{Al}_{2} \mathrm{O}_{3}$ catalyst by Breen et al. [25]. More detailed studies were published by Matter et al. [26] about $\mathrm{Cu} / \mathrm{ZnO} / \mathrm{ZrO}_{2}$ samples and, recently, by Vargas et al. [27]. All of them reported formate and methoxy groups as the predominant surface species. Hydroxyls and formaldehyde [25] were also detected as well as gas phase or weakly bonded carbon dioxide [9]. Neither methyl formate nor carbon monoxide were 
found in these studies over copper containing catalysts. On the contrary Jacobs and Davis [28] in a recent study also identified carbonate and carbon monoxide in SRM over a $\mathrm{Pt} / \mathrm{CeO}_{2}$ catalyst, but only a few data are available for a comparative evaluation, since the spectra were taken under different reaction conditions.

This work focuses on a comparative investigation of copper containing catalysts supported on different materials in the steam reforming of methanol. A microkinetic study based on the differential method and supported by DRIFT spectra will be presented in order to obtain mechanistic insight into the basic reaction steps and to show the influence of the support material on the surface chemistry.

\section{Experimental}

\subsection{Catalysts samples}

For our experiments we have decided to use commercial catalysts where possible in order to enable an easier reproducibility of our experiments. We obtained two catalyst samples by Süd-Chemie which were found to be active for methanol steam reforming at the intended reaction conditions. One $\mathrm{CuO} / \mathrm{ZnO} / \mathrm{Al}_{2} \mathrm{O}_{3}$ low-temperature shift catalyst and one $\mathrm{Cr}_{2} \mathrm{O}_{3} / \mathrm{Fe}_{2} \mathrm{O}_{3}$ high-temperature shift catalyst containing a small amount of copper oxide, denoted by SüdChemie as C 18 HA and G-3 C, respectively, were chosen. The $6 \times 3 \mathrm{~mm}$ pellets were ground and sieved to a defined particle diameter to eliminate mass transport limitation of the reaction rate.

Further $\mathrm{CuO} / \mathrm{Cr}_{2} \mathrm{O}_{3} / \mathrm{Fe}_{2} \mathrm{O}_{3}$ catalyst samples were synthesized from metal sols, prepared from the appropriate amounts of the mixed precursors $\mathrm{Cu}\left(\mathrm{NO}_{3}\right)_{2} \cdot 3 \mathrm{H}_{2} \mathrm{O}$ (a Ferak product of $>99.5 \%$ purity), $\mathrm{Cr}\left(\mathrm{NO}_{3}\right)_{3} \cdot 9 \mathrm{H}_{2} \mathrm{O}$ (Fluka, $>97 \%$ purity) and $\mathrm{Fe}\left(\mathrm{NO}_{3}\right)_{3} \cdot 9 \mathrm{H}_{2} \mathrm{O}$ (Merck, $>99 \%$ purity). The metal nitrates corresponding to $5 \mathrm{~g}$ oxidic catalyst were dissolved in $300 \mathrm{ml}$ distilled water and coprecipitated as hydroxides by addition of $\mathrm{NaOH}$ solution saturated with $\mathrm{NaHCO}_{3}$ until the remaining solution became colorless. The coprecipitate was aged in the mother liquor overnight, then it was repeatedly washed with distilled water. The resulting catalyst precursor was dried $\left(10 \mathrm{~h}\right.$ at $\left.80^{\circ} \mathrm{C}\right)$ and calcined $\left(3 \mathrm{~h}\right.$ at $\left.500{ }^{\circ} \mathrm{C}\right)$ in air, respectively.

$\mathrm{CuO} / \mathrm{ZrO}_{2} / \mathrm{CeO}_{2}(\mathrm{CZC})$ catalysts were investigated in one of our previous kinetic studies. Preparation and characterization of these materials is given in detail in the literature $[5,29]$. The CZC15 sample containing about 15 mol- $\%$ $\mathrm{CuO}$ was showing the best selectivity for SRM against $\mathrm{CO}$ formation and was therefore chosen for this study.

A catalyst consisting of copper on a silica support was prepared as fourth sample by cation exchange of tetraammine copper(II) complexes [30]. A mass of $2.5 \mathrm{~g}$ $\mathrm{Cu}\left(\mathrm{NO}_{3}\right)_{2} \cdot 3 \mathrm{H}_{2} \mathrm{O}$ dissolved in $10 \mathrm{ml}$ distilled water and $10 \mathrm{ml}$ of $25 \%$ ammonium hydroxide was slowly added to a stirred mixture of $5.0 \mathrm{~g}$ silica gel (Merck Kieselgel 100) and $30 \mathrm{ml}$ distilled water, which is corresponding to a $\mathrm{CuO}$ content of $14.1 \%$ by weight. Since the solution became nearly colorless because of the complexation of copper on the silica surface, the deep blue silica gel was washed several times with distilled water, then dried $\left(15 \mathrm{~h}\right.$ at $\left.80^{\circ} \mathrm{C}\right)$ and finally calcined $\left(10 \mathrm{~h}\right.$ at $\left.500{ }^{\circ} \mathrm{C}\right)$ in air, respectively. The final copper content of this sample was determined gravimetrically after dissolution of the $\mathrm{CuO}$ with concentrated hydrochloric acid and repeated calcination of the colorless silica gel.

The four samples $\mathrm{Cu} / \mathrm{ZnO} / \mathrm{Al}_{2} \mathrm{O}_{3}, \mathrm{Cu} / \mathrm{Cr}_{2} \mathrm{O}_{3} / \mathrm{Fe}_{2} \mathrm{O}_{3}$, $\mathrm{Cu} / \mathrm{ZrO}_{2} / \mathrm{CeO}_{2}$ and $\mathrm{Cu} / \mathrm{SiO}_{2}$ will be denoted as $\mathrm{CZA}, \mathrm{CCF}$, $\mathrm{CZC}$ and $\mathrm{CS}$, respectively, in the following. The specific surface areas of the catalyst samples were determined by nitrogen adsorption at $77 \mathrm{~K}$. A Micromeritics 2375 BET apparatus equipped with a Vacprep 061 degasser was used for this purpose. Prior to acquisition of the adsorption isotherm, the samples were first outgassed at $15 \mathrm{~Pa}$ and $120^{\circ} \mathrm{C}$ for $12 \mathrm{~h}$ in order to ensure a clean and dry surface. The specific surface areas were calculated from the BET equation, and the average pore diameters were obtained by the $\mathrm{BJH}$ method from the desorption branches of the adsorption isotherms. Chemical composition data and physical properties of the catalyst samples investigated in this study are listed in Tab. 1.

Table 1: Characteristic data of the catalysts

\begin{tabular}{|c|c|c|c|c|}
\hline & \multicolumn{4}{|c|}{ Samples (compocition [\% by weight]) } \\
\hline & $\mathrm{CZA}^{2}(\mathrm{C} 18 \mathrm{HA})$ & $C F^{a}(\mathrm{O}-3 \mathrm{C})$ & $\mathrm{CZC}^{\mathrm{b}}$ (CZC15) & $\mathrm{Cs}$ \\
\hline $\mathrm{CuO}$ & $50-60$ & $1.5-2.5$ & 69 & 11.6 \\
\hline $\mathrm{ZnO}$ & $25-35$ & - & - & - \\
\hline $\mathrm{Al}_{2} \mathrm{O}_{3}$ & $8-15$ & - & - & - \\
\hline $\mathrm{Fe}_{2} \mathrm{O}_{3}$ & - & Bal. & - & - \\
\hline $\mathrm{Cr}_{2} \mathrm{O}_{3}$ & - & $7-10$ & - & - \\
\hline$c^{*}$ & $2-3$ & $3.5-4.5$ & - & - \\
\hline $\mathrm{ZrO}_{2}$ & - & - & 39.2 & - \\
\hline $\mathrm{CeO}_{2}$ & - & - & 53.9 & - \\
\hline $\mathrm{SiO}_{2}$ & - & - & - & 88.4 \\
\hline BET surface area $\left[\mathrm{m}^{2} \mathrm{~g}^{-1}\right]$ & 68.6 & 74.2 & 102 & 270 \\
\hline Average pore diameter $[\mathrm{nm}]$ & 16.7 & 12.8 & 9.9 & 15.0 \\
\hline
\end{tabular}

${ }^{a}$ composition given by suppliers data sheet

${ }^{\mathrm{b}}$ Mastalir et al. [5] reported the molar composition of CZC catalysts

${ }^{c}$ synthetic graphite 


\subsection{Reactants}

The liquids used in this study were methanol (Roth, HPLC grade, $>99.9 \%$ purity) and distilled water. Both were degassed at $20 \mathrm{kPa}$ before use. For the fine adjustment of the molar ratio of the liquid reactant mixture, an Intersmat gas chromatograph (GC) separating with a $50 \mathrm{~m} \times 0.53 \mathrm{~mm}$ $\mathrm{CP}$-Wax column at $90^{\circ} \mathrm{C}$ and equipped with a thermal conductivity detector (TCD), was used. By using an exact calibration curve, surplus reactant mixture could be recycled and the production of waste liquid drastically reduced.

The gases used had the following minimum purities: $\mathrm{N}_{2}$ 99.99\%; $\mathrm{H}_{2} 99.999 \% ; \mathrm{CO}_{2} 99.995 \%$. They were obtained by Air Liquide.

\subsection{Experimental set-up}

Steam reforming of methanol was studied in a downstream fixed bed tubular reactor (stainless steel, i. d. $10 \mathrm{~mm}$ ). Liquid reactants were introduced by a HPLC pump (Dionex HPLC 580), gases were dosed by a mass flow controller (MFC) into the reactor. The MFC was calibrated with nitrogen, conversion factors of 1.010 and 0.784 were used for hydrogen and carbon dioxide, respectively, calculated from the ratios of their heat capacities $c_{p}$. Before feeding into the reactor, the methanol/water mixture and the gases were preheated separately up to the intended reaction temperature. The reactor and the evaporator/preheater were surrounded by an aluminium heating block in order to achieve an efficient heat transfer. Six cartridge heaters of $125 \mathrm{~W}$ each were placed in the heating block and regulated by temperature PID control. Two thermocouples of type J (Fe/Const.) were used for temperature measurement, one was located in the heating block and the other one in the catalyst bed. The catalyst was supported inside the reactor by a stainless steel grid and placed between two layers of inert Pyrex beads of the catalyst's size for better flow conditioning and heat transfer. The product mixture leaving the reactor passed two condensers at 0 and $-20^{\circ} \mathrm{C}$, respectively, in order to remove water and methanol. The dry product gas mixture then passed a mass flow meter (MFM) calibrated with a 3:1 hydrogen/carbon dioxide mixture for conversion measurement. The condensed liquid was analyzed with the Intersmat GC described in chapter 2.2 in order to detect by-products like methyl formate or dimethyl ether. The composition of the dry product gas was monitored with a Varian 3800 GC also equipped with a TCD. Helium was applied as a carrier gas, and separation was achieved with a $25 \mathrm{~m} \times 0.53 \mathrm{~mm}$ CarboPLOT P7 column at $31{ }^{\circ} \mathrm{C}$.

\subsection{Catalytic measurements}

First of all, mass transport limitation effects were quantified for CZA, by far the most active catalyst in this study. Therefore, $0.5 \mathrm{~g}$ of sieved particle size fractions from
$100-200,200-300$ and $300-450 \mu \mathrm{m}$, respectively, of the catalyst were filled into the reactor and fed with a $0.3 \mathrm{ml}$ $\mathrm{min}^{-1}$ equimolar methanol/water mixture at $220^{\circ} \mathrm{C}$. The initial conversion after a reduction period of 30 minutes could be calculated from the measured product gas flow rate.

Catalytic measurements started with a reduction period of $15 \mathrm{~h}$ at $220^{\circ} \mathrm{C}$ with a feed of $10 \mathrm{ml}_{\mathrm{n}} \mathrm{min}^{-1}$ hydrogen followed by $0.05 \mathrm{ml} \mathrm{min}^{-1}$ equimolar methanol/water mixture. The amounts and particle sizes of each catalyst for kinetic measurements are listed in Tab. 2.

Table 2: Charges of catalyst and copper during the kinetic measurements

\begin{tabular}{lllll}
\hline Sample & CZA & CCF & CZC & CS \\
\hline Catalyst mass [g] & 0.5 & 2.5 & 1.0 & 2.0 \\
Included mass of copper [8] & $0.250-0.300$ & $0.038-0.063$ & 0.069 & 0.232 \\
Particle aize [ $\mu \mathrm{m}]$ & $200-300$ & $200-300$ & $100-300$ & $63-200$ \\
\hline
\end{tabular}

After the catalyst aging period, which took at least several days, kinetic measurements were conducted. Therefore the molar ratio of the reactants was varied with and without addition of nitrogen, hydrogen and carbon dioxide as follows:

- $\mathrm{CH}_{3} \mathrm{OH} / \mathrm{H}_{2} \mathrm{O}$ molar ratio from 1:9 up to 9.5:1

- $\mathrm{N}_{2}$ and $\mathrm{H}_{2}$ addition from 20 up to $80 \%$

- $\mathrm{CO}_{2}$ addition from 20 up to $60 \%$

In order to keep the conversion of the minor component below $10 \%$, the liquid flow rate was adjusted between 0.05 and $0.5 \mathrm{ml} \mathrm{min}^{-1}$, gases were added with a flow rate of $50-250 \mathrm{ml}_{\mathrm{n}} \mathrm{min}^{-1}$. The molar ratios were not changed systematically (e.g. increasing water content) but randomly, in order to avoid tendencies originating from the experimental process or misinterpretation of catalyst aging effects. However, the gases were added to the given $\mathrm{CH}_{3} \mathrm{OH} / \mathrm{H}_{2} \mathrm{O}$ composition in increasing concentrations (20/40/60/80\%) in the order $\mathrm{N}_{2}, \mathrm{H}_{2}, \mathrm{CO}_{2}$.

\subsection{DRIFTS experiments}

In situ diffuse reflectance infrared spectroscopy was conducted using the Graseby Specac Diffuse Reflectance Optics "The Selector" and an "Environmental Cell" (zinc selenide window). This unit operates with a Bruker ifs 66 FTIR-spectrometer equipped with a mercury cadmium telluride (MCT) detector. Both reactants were dosed via saturators (water: $30{ }^{\circ} \mathrm{C}$, methanol: $4{ }^{\circ} \mathrm{C}$ ) in a helium stream. Their concentrations in the combined stream were controlled by the adjustment of three mass flow controllers $\left(\mathrm{He}_{\text {sat,methanol}}, \mathrm{He}_{\text {sat,water }}\right.$ and $\left.\mathrm{He}\right)$, the calculations were based on the Antoine equation [31]. The reactants overall concentration was $4 \%$ in a total flow of $10-15 \mathrm{ml} \mathrm{min}^{-1}$. The sample holder was filled with $15-50 \mathrm{mg}$ of the $<25 \mu \mathrm{m}$ catalyst powder, depending on its density. Each catalyst was reduced for $2 \mathrm{~h}$ in a $4 \%$ methanol flow at $250{ }^{\circ} \mathrm{C}$, then cooled to $220^{\circ} \mathrm{C}$ and kept in the methanol flow overnight in order to remove the high amount of adsorbed water on 
the catalyst surface via SRM reaction and reach steady state conditions. DRIFTS measurements were conducted beginning at 4:1 methanol excess and decreasing methanol to water ratio. The reaction products were analyzed on-line by MS (Pfeiffer Omnistar). DRIFT spectra were collected after steady-state conditions were achieved. Typically, 1000 scans were averaged at a resolution of $4 \mathrm{~cm}^{-1}$ due to a low signal-to-noise ratio of the reduced copper catalysts. The single channel sample spectra were divided by a KBr background spectrum, which was taken prior to in-situ measurements. The resulting spectra were transformed into the Kubelka-Munk function.

\section{Results and discussion}

\subsection{Mass transport limitation}

For microkinetic modelling it is important to eliminate mass transport limitation of the reaction rate. Several authors reported diffusion limitation in SRM over $\mathrm{Cu} / \mathrm{ZnO} / \mathrm{Al}_{2} \mathrm{O}_{3}$ catalysts. In a previous study on a different commercial catalyst (Süd-Chemie $\mathrm{MeOH} 1$ ) a reduced reaction rate has been observed at a particle size of $0.71-$ $1.00 \mathrm{~mm}[8]$ and at a temperature of $250{ }^{\circ} \mathrm{C}$. Lee et al. predicted mass transport limitations at a temperature of $240{ }^{\circ} \mathrm{C}$ for their catalyst (Synetix 33-5) from theoretical calculations [10]. However, besides a larger particle diameter in both of the studies, their catalysts were about three to five times more active than the $\mathrm{Cu} / \mathrm{ZnO} / \mathrm{Al}_{2} \mathrm{O}_{3}$ catalyst investigated in this study which may explain their results. On the contrary, Jiang et al. [32] did not find any dependence of the particle diameter in a range of $150-190 \mu \mathrm{m}$ on the reaction rate in their studies with commercial catalysts (BASF S3-85), although using an even more active catalyst and working at temperatures of $160-260^{\circ} \mathrm{C}$. This result was also reported by Peppley et al. [6], investigating SRM over a $\mathrm{Cu} / \mathrm{ZnO} / \mathrm{Al}_{2} \mathrm{O}_{3}$ catalyst (BASF K3-110) in the same temperature range with a particle size of $710-850 \mu \mathrm{m}$.

We applied the Weisz-Prater criterion using the Weisz modulus $\Psi^{\prime}$ as dimensionless quantity for an estimation of diffusion limitations [33] and confirmed our results with experimental determination of the influence of pore diffusion for the most active catalyst CZA. The Weisz modulus (Eq. 5), which gives the ratio of the reaction rate to the diffusion rate in a porous catalyst pellet, is

$$
\Psi^{\prime}=L^{2} \cdot \frac{m+1}{2} \cdot \frac{r_{\mathrm{eff}} \cdot \rho_{\mathrm{cat}}}{D_{\mathrm{eff}, \mathrm{M}} \cdot c_{\mathrm{M}}}
$$

where $L$ is the characteristic length (m) given by one third of the particle radius for spherical particles, $m$ the reaction order of methanol, $r_{\text {eff }}$ the measured reaction rate $\left(\mathrm{mol} \mathrm{s}^{-}\right.$ $\left.{ }^{1} \mathrm{~kg}^{-1}\right), \rho_{\text {cat }}$ the catalyst density $\left(\mathrm{kg} \mathrm{m}^{-3}\right), D_{\text {eff,M }}$ the effective diffusivity of methanol $\left(\mathrm{m}^{2} \mathrm{~s}^{-1}\right)$ and $c_{\mathrm{M}}$ the gas phase concentration of methanol at the catalyst surface $\left(\mathrm{mol} / \mathrm{m}^{3}\right)$. At ambient pressure the diffusivity in porous solids is reduced to Knudsen diffusivity at pore diameters $<100 \mathrm{~nm}$. With a typical value for the tortuosity of $\tau=3.5$ [34] and the measured porosity of $\varepsilon=0.7$ we determined the effective Knudsen diffusivity of methanol to be $D_{\mathrm{K}, \mathrm{eff}, \mathrm{M}}=6.4 \cdot 10^{-7} \mathrm{~m}^{2} \mathrm{~s}^{-1}$. Since a reaction order of 0.5 for methanol results in Weisz moduli of $\Psi^{\prime}<<1$ for the chosen particle size fraction, the Weisz-Prater criterion predicts no mass transport limitation for our reaction conditions and an effectiveness factor of $\eta \approx 1$.

This theoretical result could be confirmed by experimental tests. No change of the reaction rate was observed when varying the particle diameter of CZA in the range of $100-450 \mu \mathrm{m}$ indicating that there is no mass transport limitation at $220^{\circ} \mathrm{C}$. Mass transport limitation in CZC was determined to be insignificant in our previous study [5]. Using a small particle size fraction of 100-300 $\mu \mathrm{m}$, an influence on the reaction rate can be excluded. Since the most active catalysts proved to be gradientless under the chosen reaction conditions, similar tests with $\mathrm{CCF}$ and $\mathrm{CS}$ were omitted because of lower activity, similar pore diameter, smaller particle size (CS) and very low copper content (CCF).

\subsection{Catalyst aging}

It is well known that copper-catalysts used in methanol synthesis and also in the steam reforming of methanol deactivate rapidly during their initial period of operation. Irreversible alloy formation of the active copper species with support material and thermal sintering of small $\mathrm{Cu}$ particles and thereby the reduction of the active surface area are two of the possible reasons $[35,36]$. E.g. Zhang et al. [37] reported the positive effect of ceria on the preservation of a high copper dispersion and thereby an enhanced long term stability. The same effect was found by Szyzibalski et al. [38] using zirconia as support material. Another factor is the deposition of coke on the catalyst surface. Liu et al. [18] removed up to $1.7 \mathrm{wt} . \%$ coke from their $\mathrm{Cu} / \mathrm{CeO}_{2}$ catalyst by re-calcination in air and again reached the initial activity. Coke formation was also observed by XPS and even fitted with a kinetic model for a $\mathrm{Cu} / \mathrm{ZnO} / \mathrm{Al}_{2} \mathrm{O}_{3}$ catalyst by Agarwal et al. [39]. As a fourth reason, a change in the oxidation state of copper from $\mathrm{Cu}$ (II) to $\mathrm{Cu}(0)$ was made responsible for catalyst deactivation by Choi et al. [17], who observed the copper reduction with XPS during the first $100 \mathrm{~h}$ of operation of their $\mathrm{Cu} / \mathrm{ZnO} / \mathrm{Al}_{2} \mathrm{O}_{3}$-catalyst.

Because kinetic measurements took about one week for each catalyst, a change in catalyst activity during this time period had to be excluded. Therefore the catalysts aged for several days under identical reaction conditions until they reached constant conversion in SRM. The deactivation of the samples after the reduction period is presented in Fig. 2.

From Fig. 2 it can be clearly seen, that each catalyst looses about $30-40 \%$ of the initial activity after a time on stream of $100 \mathrm{~h}$. While CZA, CCF and CZC reach a constant activity, CS still seemed to deactivate and not to be a 
stable catalyst under SRM conditions. Concerning CZC it may be interesting to remark, that the deactivation at $220^{\circ} \mathrm{C}$ stopped earlier and the catalyst kept a comparatively higher activity than at $250^{\circ} \mathrm{C}[5]$, where the same catalyst lost more than half of its initial activity and became stable after $200 \mathrm{~h}$ on stream. This result is in agreement with the observation of thermal sintering of the copper particles during SRM conditions especially at higher temperatures.

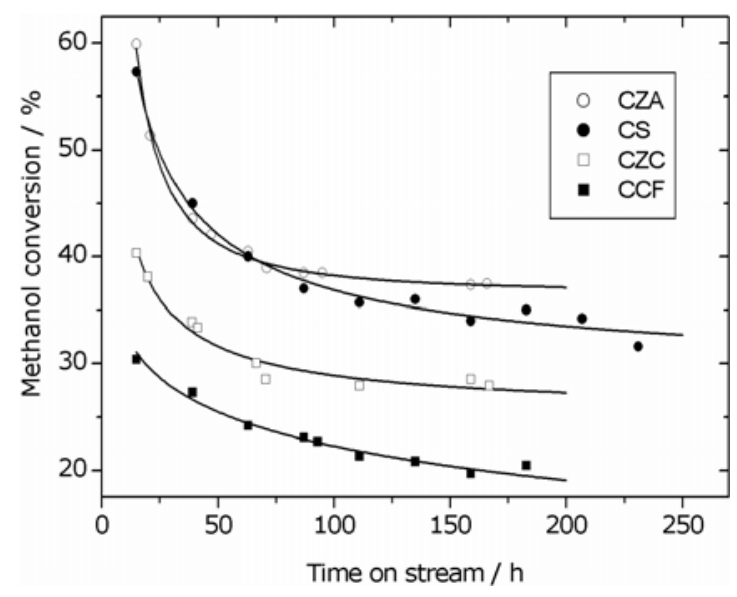

Figure 2: Initial catalyst deactivation of copper-catalysts during $\mathrm{SRM}$ as a function of time on stream $\left(\mathrm{m}_{\mathrm{CZA}}=0.5 \mathrm{~g}, \mathrm{~m}_{\mathrm{CCF}}=2.5 \mathrm{~g}\right.$, $\mathrm{m}_{\mathrm{CZC}}=1.0 \mathrm{~g}, \mathrm{~m}_{\mathrm{CS}}=2.0 \mathrm{~g}, \mathrm{~T}=220^{\circ} \mathrm{C}, \mathrm{p}=1 \mathrm{bar}, \mathrm{w}=0.05 \mathrm{ml} \mathrm{min} \mathrm{m}^{-}$ $\left.{ }^{1}, \mathrm{MeOH} / \mathrm{H}_{2} \mathrm{O}=1\right)$.

\subsection{DRIFTS-experiments}

A series of DRIFT spectra were collected in order to obtain information about the surface reactions and intermediates during SRM. Based on previous studies [9,25-27] and the proposed mechanism over $\mathrm{Cu} / \mathrm{ZnO} / \mathrm{Al}_{2} \mathrm{O}_{3}$ catalysts the appearance of hydroxyls, methoxy and formate groups was expected as well as carbon dioxide as gas phase or weakly bonded surface species. One aim of this study was a decision as to whether the reaction occurs mainly via dioxomethylene or via methyl formate by the observation of one of these species on the catalyst surface. The reactant composition was varied from methanol excess to water excess in order to observe a dependence of the band areas on the reactants partial pressure and thereby support the mechanistic model as basis for the kinetic model.

The process of DRIFT spectra conversion and manipulation is shown in Fig. 3 exemplarily for CZA and a feed composition of $\mathrm{MeOH} / \mathrm{H}_{2} \mathrm{O}=1: 1$. The raw data of the DRIFT spectra from the catalyst before feed addition (a) and in-situ during SRM reaction (b) were both KubelkaMunk transformed into spectra (c) and (d), respectively. As can be seen from the strongly different intensity, a simple substraction of these spectra would result in negative bands, so spectrum (c) was weighted with the factor 0.35 prior to the substraction from spectrum (d). The weighting factor was determined individually, using the carbonate band at $1350-1500 \mathrm{~cm}^{-1}$ as orientation. The resulting dif- ference spectrum (e) was finally base-line adjusted (f) for clarity and comparability, if necessary.

The DRIFT spectrum of CZA is of relatively low quality, which may be ascribed to the high copper content of this catalyst. Peppley et al. [9] also presented a spectrum of a high $\mathrm{Cu}$ content $\mathrm{Cu} / \mathrm{ZnO} / \mathrm{Al}_{2} \mathrm{O}_{3}$ catalyst, with comparatively high signal to noise ratio. The reflectance, which was $>10 \%$ in a wide spectral range for the oxidized catalyst, suffered a drastic drop during the reduction period (see also Fig. 3, (a) and (b)) and the resulting spectra allow only cautious statements about the absence of surface intermediates. A dilution of the catalyst with inert $\alpha$-alumina powder had no effect on the signal-to-noise ratio. Vargas et al. [27] also observed a decreased intensity over a reduced $\mathrm{Cu} / \mathrm{ZnO} / \mathrm{Al}_{2} \mathrm{O}_{3}$ catalyst compared to the oxidized sample.
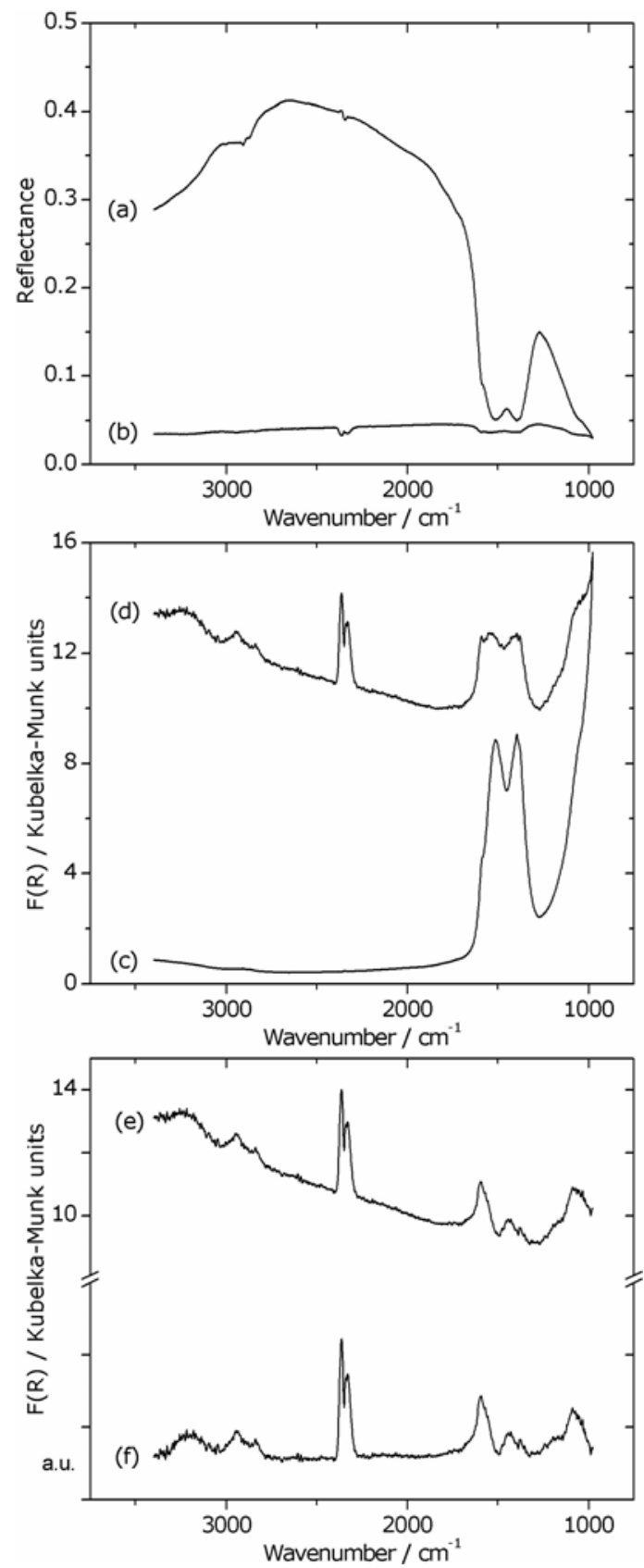

Figure 3: Process of DRIFT spectra editing prior to presentation, exemplarily shown for CZA with a feed composition of $\mathrm{MeOH} / \mathrm{H}_{2} \mathrm{O}=1: 1$ 

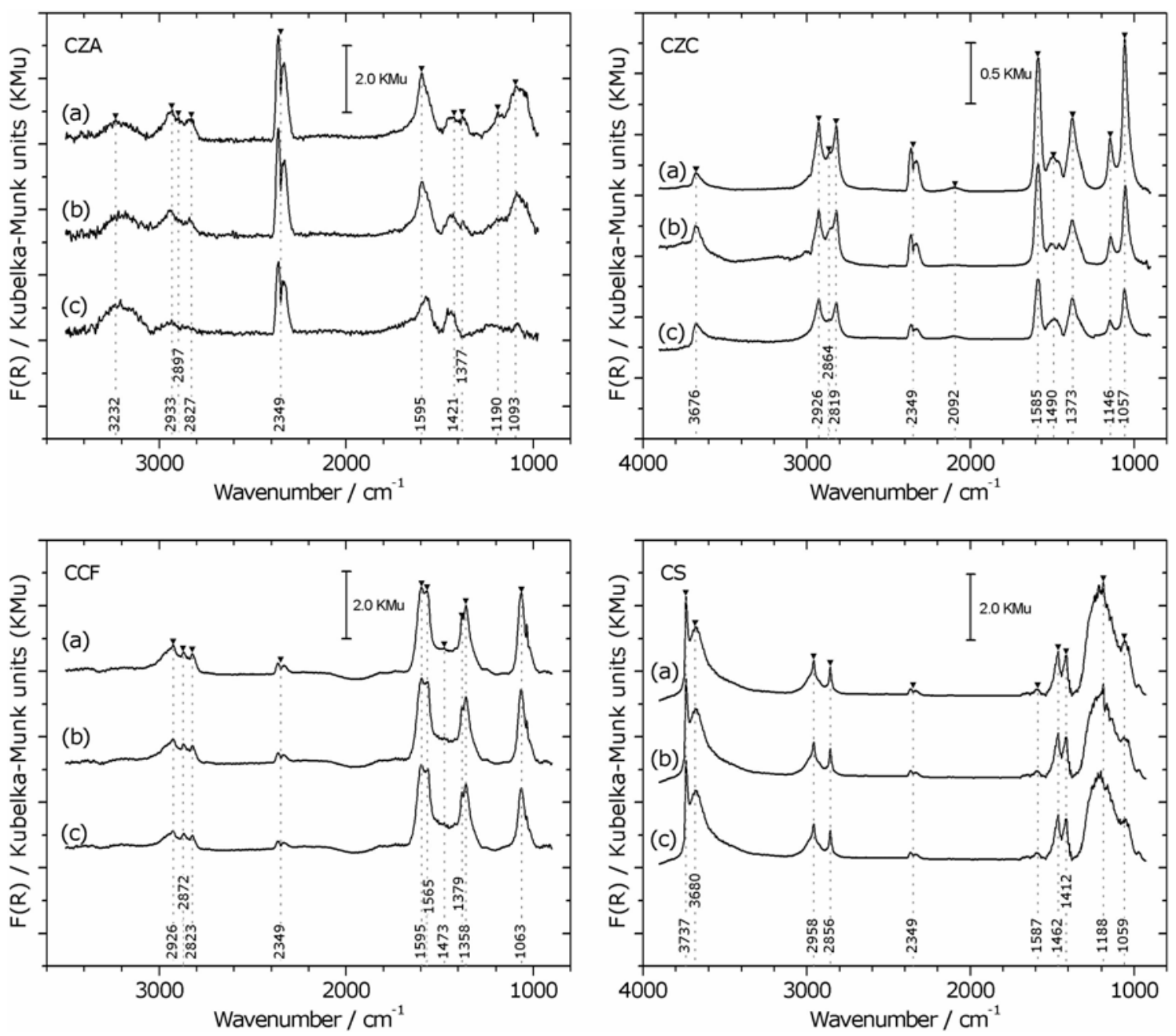

Figure 4: DRIFT spectra of the investigated catalysts $\mathrm{CZA}, \mathrm{CCF}, \mathrm{CZC}$ and $\mathrm{CS}$, collected at $220^{\circ} \mathrm{C}$, reactant overall concentration $4 \%$ in helium. (a) $\mathrm{MeOH} / \mathrm{H}_{2} \mathrm{O}=4: 1$, (b) $\mathrm{MeOH} / \mathrm{H}_{2} \mathrm{O}=1: 1$, (c) $\mathrm{MeOH} / \mathrm{H}_{2} \mathrm{O}=1: 4$, respectively.

As can be seen from Fig. 4 the same intermediates were found on each investigated copper-based catalyst. Surface hydroxyls are present on the catalysts surfaces with broad features at $3000-3800 \mathrm{~cm}^{-1}$ except for CCF. Also identified on every surface was the characteristic pattern of two methoxy bands bordering one formate band at 2800 $3000 \mathrm{~cm}^{-1}$ from $\mathrm{C}-\mathrm{H}$ stretching modes, respectively. The bands around $2349 \mathrm{~cm}^{-1}$ are attributed to the two branches of the rotation vibration spectrum of gaseous carbon dioxide. Surface copper carbonyls were only observed on CZC and CS with a feature at $2092 \mathrm{~cm}^{-1}$. Surprisingly no CO could be detected on the surface of CCF although it showed the worst selectivity in the on-line analysis during the DRIFTS measurements as well as in the kinetic measurements. The region between 1000 and $1600 \mathrm{~cm}^{-1}$ contains bands of carbonates as well as features from methoxy and formate $\mathrm{C}-\mathrm{O}$ stretching and $\mathrm{C}-\mathrm{H}$ bending modes. The bands are summarized and assigned to surface species and their vibrational modes in Tab. 3, where also the references for the assignment are given.

Over CCF the asymmetric OCO stretching band and the $\mathrm{CH}$ bending band of formate species appear to be divided into two neighbored bands at $1358 / 1379 \mathrm{~cm}^{-1}$ and
$1565 / 1595 \mathrm{~cm}^{-1}$, respectively. This can indicate either monodentate and bidentate formate adsorption [40] or the parallel adsorption of formate on two different kinds of surfaces [27] which may be present in the CCF catalyst. On the other hand there is also a shoulder at about $1360 \mathrm{~cm}^{-1}$ observable on CZC. This feature as well as the band at $1358 \mathrm{~cm}^{-1}$ on CCF may also be assigned to symmetric OCO stretching.

Moreover these spectra can be evaluated semiquantitatively. Except for CS, whose DRIFT spectra seem to be independent from the feed composition, the band areas of methoxy groups clearly increase with increasing methanol partial pressure. In contrast, the intensity of surface hydroxyls decreases since the overall concentration of the reactants was kept constant at $4 \%$. An integration of the hydroxyl bands (3232 and $3676 \mathrm{~cm}^{-1}$ for CZA and CZC, respectively) and the bands of methoxy groups (1093, 1057 and $1063 \mathrm{~cm}^{-1}$ for CZA, CZC and CCF, respectively) after fitting results in linear correlations of the band areas with the methanol (methoxy groups) and water (hydroxyls) partial pressure in the feed with a good accuracy. This confirms the appearance of the corresponding adsorption terms in the mechanistic rate equation from independent spectro 
Table 4: Band areas and ratios of the $v(\mathrm{CH})_{\mathrm{s}}$ bands of the formate and the methoxy groups

\begin{tabular}{|c|c|c|c|c|c|c|c|c|c|c|c|}
\hline \multirow[t]{2}{*}{ Species } & \multirow[t]{2}{*}{$\mathrm{Mode}^{\mathrm{a}}$} & \multirow[t]{2}{*}{ CZA } & \multirow[t]{2}{*}{$\mathrm{CCF}$} & \multirow[t]{2}{*}{$\mathrm{CZC}$} & \multirow[t]{2}{*}{ CS } & \multirow{2}{*}{$\frac{\mathrm{Cu} / \mathrm{ZnO} / \mathrm{ZrO}{ }_{2}}{[26]}$} & \multirow{2}{*}{$\frac{\mathrm{Cu} / \mathrm{ZnO} / \mathrm{Al}_{2} \mathrm{O}_{3}}{[27]}$} & \multirow{2}{*}{$\frac{\mathrm{Fe}_{2} \mathrm{O}_{3} / \mathrm{SiO}_{2}}{[52]}$} & \multirow{2}{*}{$\frac{\mathrm{P} / \mathrm{CeO} 2}{[3]}$} & \multicolumn{2}{|c|}{$\mathrm{Cu} / \mathrm{SiO}_{2}$} \\
\hline & & & & & & & & & & [40] & [39] \\
\hline \multirow[t]{5}{*}{ Methoxy } & $v\left(\mathrm{CH}_{2}\right.$ & 2933 & 2926 & 2926 & 2958 & 2926 & 2950 & & 2920 & 2960 & 2951 \\
\hline & $v\left(\mathrm{CH}_{k}\right)$ & 2827 & 2823 & 2819 & 2856 & 2821 & 2830 & & 2820 & 2859 & 2851 \\
\hline & $8(\mathrm{CH})_{a}$ & & & & 1462 & & & $\begin{array}{l}1466 \\
1438\end{array}$ & & 1463 & \\
\hline & $\rho\left(\mathrm{CH}_{3}\right)$ & 1190 & & 1146 & (1188) & & 1190 & & & & \\
\hline & $v(C O)$ & 1093 & 1063 & 1057 & 1059 & 1047 & 1081 & & 1080 & & \\
\hline \multirow[t]{2}{*}{ Hydroxy } & $x(\mathrm{OH})$ & & & & 3737 & & 3735 & & & 3738 & \\
\hline & $x(\mathrm{OH} \cdot \cdot \mathrm{O})$ & 3232 & & 3676 & 3680 & & 3445 & & 3650 & 3650 & \\
\hline \multirow[t]{5}{*}{ Formate } & $x(\mathrm{CH})$ & 2897 & 2872 & 2864 & & 2871 & 2896 & & 2830 & & 29002 \\
\hline & $v(O C O)_{a}$ & 1595 & 1595 & 1585 & 1587 & 1600 & 1594 & 1567 & 1580 & & 1564 \\
\hline & & & 1565 & & & & 1610 & & & & \\
\hline & $8(\mathrm{CH})$ & 1377 & 1379 & 1373 & & 1357 & 1390 & 1377 & 1350 & & \\
\hline & & & 1358 & & & & & & & & \\
\hline Grs phase or weakly & & & & & & 2359 & & & & & \\
\hline adsorbed carbon & & & & & & 2327 & & & & & \\
\hline dioxide & & & & & & & & & & & \\
\hline $\begin{array}{l}\text { Grs phase carton } \\
\text { dioxide }\end{array}$ & & 2349 & 2349 & 2349 & 2349 & & 2341 & & & & \\
\hline Carbonyls & & & & 2092 & & 2095 & & & & & \\
\hline Carbonate & & 1421 & & 1490 & 1412 & & 1550 & & 1460 & & 1415 \\
\hline & & & & & & & 1395 & & & & \\
\hline
\end{tabular}

${ }^{\mathrm{d}} v$ : stretch; $\delta$ : bend; $\rho$ : rock

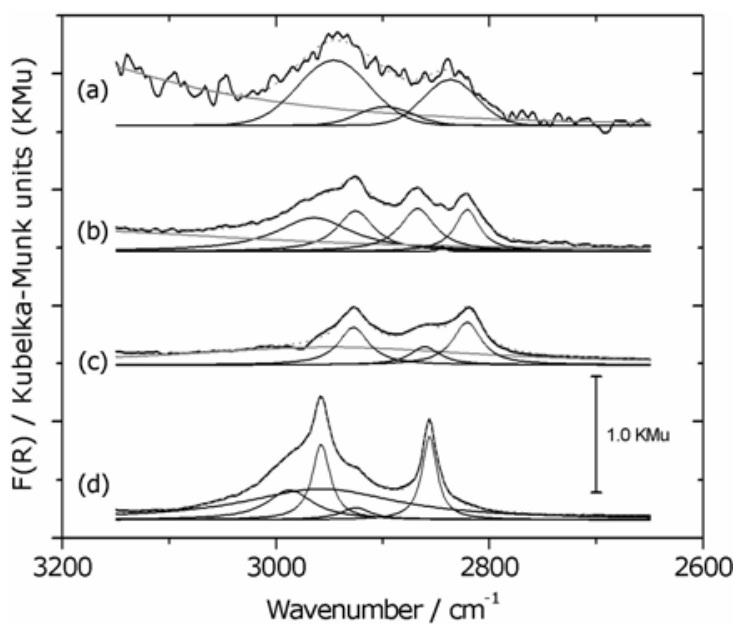

Figure 5: Fit of spectra (b) of each catalyst from Fig. 3; (a) CZA; (b) $\mathrm{CCF}$; (c) $\mathrm{CZC}$; (d) $\mathrm{CS}$; Feed: $4 \%$ reactants $\left(\mathrm{MeOH} / \mathrm{H}_{2} \mathrm{O}=1: 1\right)$, $220^{\circ} \mathrm{C}$.

scopic experiments. As expected the signal of the gas phase carbon dioxide correlates with the measured conversion in this experimental series and is stronger with higher methanol partial pressure. The latter indicates that the reaction rate depends more on the methanol than on the water partial pressure, since other reaction parameters (temperature, contact time) were kept constant during this experimental series. However, bands of methyl formate, expected at 1666 and $1726 \mathrm{~cm}^{-1}$ [41], which was only detected by MS over CS in traces and only in case of high methanol surplus in the feed, or dioxomethylene, expected at 1405 and 2765 $\mathrm{cm}^{-1}$ [40], were absent as well as bands of formaldehyde, expected at $1148 \mathrm{~cm}^{-1}$ [26], one other "missing" intermediate in the assumed reaction pathway. It appears that these species either do not participate in the SRM reaction mechanism or transform too rapidly for detection with infrared spectroscopy, and this part of the reaction network cannot be clarified using this technique.

Table 4: Band areas and ratios of the $v(\mathrm{CH})_{\mathrm{s}}$ bands of the formate and the methoxy groups

\begin{tabular}{llllll}
\hline Catalys & $v(\mathrm{CH})_{5}$ methoxy & Band area & $v(\mathrm{CH})_{5}$ formate & Band area & Ratio \\
\hline CZA & 2836 & 24.7 & 2897 & 10.1 & 2.5 \\
CCF & 2820 & 15.8 & 2867 & 23.2 & 0.7 \\
CZC & 2821 & 18.8 & 2860 & 8.3 & 2.3 \\
CS & 2855 & 19.4 & 2925 & 5.6 & 3.5 \\
\hline
\end{tabular}

Another observation concerning the range from 2600 - $3200 \mathrm{~cm}^{-1}$ is the signal of the formate group, which is comparatively strong on CCF and nearly invisible on the other three catalysts. Since the absolute band area is not meaningful for itself without knowledge of the extinction coefficients, the ratio of the band areas from the symmetric $v(\mathrm{CH})$ bands of the formate groups and the methoxy groups was calculated from the fits of the spectra, which are presented in Fig. 5 and in Tab. 4. The wavenumbers given in the table result from the fits and may differ slightly from the numbers given in Fig. 5.

It can be seen clearly from these ratios, that the surface of CCF is relatively heavily covered with formate groups compared to the surfaces of the other catalysts. This means that formate groups on this catalyst are relatively stable and their decomposition by dehydrogenation may have an influence on the overall reaction rate. In addition to the results of the kinetic model discrimination, which will be discussed later, this is a confirmation for a difference in the rate determining step of methanol steam reforming over $\mathrm{Cu} / \mathrm{Cr}_{2} \mathrm{O}_{3} / \mathrm{Fe}_{2} \mathrm{O}_{3}$ compared to already well investigated $\mathrm{Cu} / \mathrm{ZnO} / \mathrm{Al}_{2} \mathrm{O}_{3}$ or $\mathrm{Cu} / \mathrm{SiO}_{2}$ systems.

Further information from the fits is the presence of one more methoxy-related band at $2987 \mathrm{~cm}^{-1}$ (CS) and at $2964 \mathrm{~cm}^{-1}(\mathrm{CCF})$. These bands, not observed on CZA and $\mathrm{CZC}$, may also be attributed to $\mathrm{C}-\mathrm{H}$ stretching vibrations . 


\subsection{Kinetic modelling}

\subsubsection{Contact time}

For kinetic modelling the knowledge of the contact time is an essential condition. Especially for isobaric gas phase reactions with expanding or contracting volume due to a change in the total mole number the determination may become difficult. Measurements in the high conversion regime need numerical integration since the resulting deviation is dependent on the conversion and will cause a systematic error. This may be irrelevant for kinetics developed for technical application but for mechanistic studies the determination of the contact time needs at least as much attention as the analysis of the product mixture. In our case we measured mainly differential conversions of $<10 \%$ so conversion can be regarded directly proportional to the contact time. We also had to consider the molar ratio $\lambda$ of the reactants and added gases like $\mathrm{N}_{2}, \mathrm{H}_{2}$ and $\mathrm{CO}_{2}$. Measuring in the linear range, the contact time can be calculated from Eq. 6:

$$
\tau=\frac{V_{\mathrm{R}}}{\dot{V}_{0}} \cdot \frac{1}{B \cdot X} \cdot \ln \left(\frac{A+B+B \cdot X}{A+B}\right)
$$

where $V_{\mathrm{R}}$ is the catalyst bed volume $\left(\mathrm{m}^{3}\right), \dot{V}_{0}$ the initial gas flow rate $\left(\mathrm{m}^{3} \mathrm{~s}^{-1}\right)$ and $X$ the conversion of the reactant present as minor component. The coefficients $A$ and $B$ depend on the molar ratio of methanol and water $\lambda=n_{\mathrm{MeOH}} / n_{\mathrm{H} 2 \mathrm{O}}$ and are given by

$$
\begin{aligned}
& A \\
& \lambda \leq 1 \quad x_{\mathrm{gas}, 0}+\left(1-x_{\mathrm{gas}, 0}\right) \cdot \frac{1-\lambda}{1+\lambda} \quad\left(1-x_{\mathrm{gas}, 0}\right) \cdot \frac{2 \lambda}{1+\lambda} \\
& \lambda \geq 1 \quad x_{\mathrm{gas}, 0}-\left(1-x_{\mathrm{gas}, 0}\right) \cdot \frac{1-\lambda}{1+\lambda} \quad\left(1-x_{\mathrm{gas}, 0}\right) \cdot \frac{2}{1+\lambda}
\end{aligned}
$$

where $x_{\text {gas }, 0}$ is the initial molar ratio of added gas. Fig. 6 shows the deviation of the contact time with increasing conversion in SRM calculated from Eq. 6 and from numerical integration as done in our previous work [5].

\subsubsection{Microkinetic model}

The development of a possible microkinetic model for methanol steam reforming over a commercial $\mathrm{Cu} / \mathrm{ZnO} / \mathrm{Al}_{2} \mathrm{O}_{3}$ catalyst is described in detail by Peppley et al. [9]. Since most of our experimental data can be explained using this proposed reaction mechanism, it was taken as basis of our investigations. The catalytic cycle begins with the dissociative adsorption of methanol on the catalyst surface, which is assumed to include two distinct

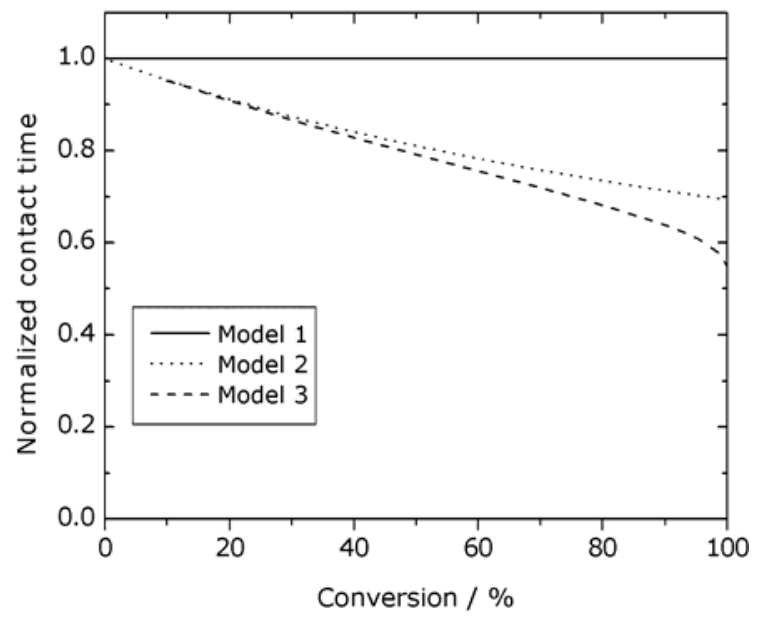

Figure 6: Predicted reduction of the contact time during SRM as a function of conversion due to increase of total mole number, calculations for equimolar reactant mixture. Model 1: contact time related to initial flow rate (no change in mole number, full line); Model 2: contact time calculated from Eq. 6 (short dashed line); Model 3: contact time from numerical integration [5] (long dashed line).

types of active sites. One kind of sites is responsible for hydrogen adsorption (type 1a) and one for the adsorption of all the other intermediates (type 1), which are exclusively oxygen-bonded. In this study, the adsorption sites will be denoted as type A and B instead of 1 and 1a in [9], respectively. Jung and Bell [23] in their study of methanol synthesis assign the adsorption of hydrogen to the metallic copper surface whereas the oxygenate chemistry takes place on the ceramic support (in this case $\mathrm{ZrO}_{2}$ ). A similar assignment in case of methanol steam reforming is possible due to the microreversibility principle. Matter et al. [26] propose methanol adsorption over hydroxylated surfaces via water formation. From our experiments this cannot be excluded, since at the end a similar reaction rate law would result. However, the methoxy group suffering dehydrogenation as the rate determining step of the overall reaction, was also found by Lee et al. [10] and Jiang et al. [32] in their kinetic studies. The formed formaldehyde is immediately attacked by a methoxy group, resulting in the intermediate methyl formate [42,43], which was observed in several studies of SRM as by product in traces, exclusively in case of methanol surplus in the reactant mixture. One other reaction pathway towards methyl formate is described by the reaction of methanol with formate groups, which was identified by Busca et al. [44] over $\mathrm{VO}_{\mathrm{x}} / \mathrm{TiO}_{2}$ catalysts during methanol decomposition and partial oxidation. This reaction pathway appears less feasible over partly reduced copper catalysts due to the limited and doubtful assignability of kinetic data from these greatly different catalyst systems and reaction conditions. However, methyl formate decomposes in contact with hydroxyl groups to methoxy and formate groups. One other reaction mechanism is given by Takezawa, Takahashi et al. [19,20], who propose the attack of formaldehyde by surface hydroxyls, which results in the formation of dioxomethylene as reaction intermedi 


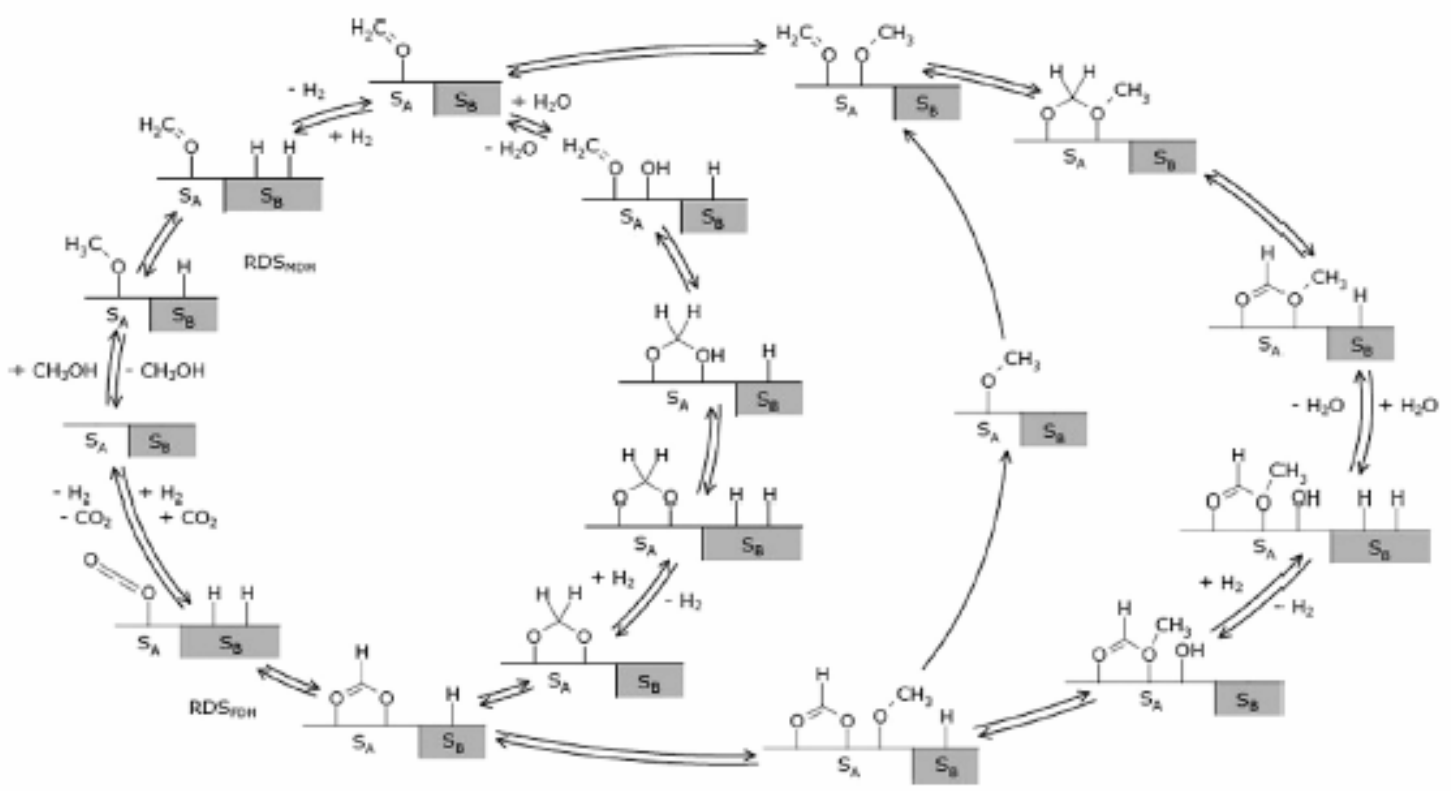

Figure 7: Catalysis cycle of methanol steam reforming on the basis of the investigation s of Jiang [15], Peppley [9] and Takezawa [19] including different kinds of reactive surface sites $\mathrm{A} \square$ and $\mathrm{B} \square$

ate. Dioxomethylene, the intermediate of the reverse methanol synthesis reaction, is supposed to dehydrogenate into a formate group. However, neither methyl formate nor dioxomethylene were observed in the DRIFTS study and thereby will not appear in the adsorption term of the microkinetic rate law, which then looks identical in this case for both reaction mechanisms. The formate group dehydrogenates again in order to release carbon dioxide from the type A surface. The accumulated hydrogen desorbs molecularly from the type B surface.

The whole catalysis cycle of methanol steam reforming is given schematically in Fig. 7. Adopting the HougenWatson formalism, based on the Langmuir adsorption isotherms, the kinetics of this catalysis cycle can be formulated making the following assumptions:

(1) The dehydrogenation of the methoxy group is the RDS, all the other elemental reactions are in thermodynamic equilibrium

(2) Oxygenates adsorb competitively and mostly in one monolayer on surface A, whereas hydrogen adsorbs dissociatively on surface B

(3) Only adsorbates observed in the DRIFTS study are considered in the adsorption term, additionally the adsorption of carbon dioxide is taken into account

(4) Measuring in the low conversion regime the reverse reaction is negligible

The microkinetic rate equation of SRM is then given by Eq. 7, in which the index MDH means methoxy dehydrogenation.

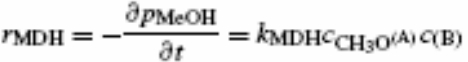

$$
\begin{aligned}
& =\left(k_{\mathrm{MDH}} C_{\mathrm{S}_{\mathrm{A}}}^{\mathrm{T}} C_{\mathrm{S}_{\mathrm{B}}}^{\mathrm{T}} K_{\mathrm{CH}_{3} \mathrm{O}^{(\mathrm{A})}}^{+}\left(p_{\mathrm{CH}_{3} \mathrm{OH}} / p_{\mathrm{H}_{2}}^{1 / 2}\right)\right) \\
& /\left((1+\underbrace{K_{\mathrm{CH}_{3} \mathrm{O}^{(\mathrm{A})}}^{*}\left(p_{\mathrm{CH}_{3} \mathrm{OH}} / p_{\mathrm{H}_{2}}^{1 / 2}\right)}_{\text {methoxy }}\right. \\
& +\underbrace{K_{\mathrm{OH}^{(A)}}^{*}\left(p_{\mathrm{H}_{2} \mathrm{O}} / p_{\mathrm{H}_{2}}^{1 / 2}\right)}_{\text {hydroxy }}+\underbrace{K_{\mathrm{HCOO}}^{*}{ }^{\mathrm{A})} p_{\mathrm{CO}_{2}} p_{\mathrm{H}_{2}}^{1 / 2}}_{\text {formute }} \\
& +\underbrace{K_{\mathrm{CO}_{2}^{(A)} p \mathrm{CO}_{2}}}_{\text {carton dioxide }})\left(1+K_{\mathrm{H}^{(\mathrm{B})}}^{1 / 2} p_{\mathrm{H}_{2}}^{1 / 2}\right)) .
\end{aligned}
$$

where $k_{\mathrm{MDH}}$ is the rate constant and $C_{\mathrm{S}_{\mathrm{A}}}^{\mathrm{T}}$ and $C_{\mathrm{S}_{\mathrm{B}}}^{\mathrm{T}}$ are the total concentrations of type A and type B adsorption sites, respectively. Since these three values cannot be determined individually by parameter fitting, their product $k^{*}$ was taken for this process (Eq. 8).

$$
k^{*}=k_{\mathrm{MDH}} C_{\mathrm{S}_{\mathrm{A}}}^{\mathrm{T}} C_{\mathrm{S}_{\mathrm{B}}}^{\mathrm{T}}
$$

The combined adsorption constants $K^{*}$ given in the adsorption term are defined as (Eq. 9-11)

$$
K_{\mathrm{CH}_{3} \mathrm{O}^{(\mathrm{A})}}^{*}=\frac{K_{\mathrm{CH}_{3} \mathrm{OH}}{ }^{(\mathrm{A}, \mathrm{B})}}{K_{\mathrm{H}_{2}{ }^{(\mathrm{B})}}^{1 / 2}}
$$


$K_{\mathrm{HCOO}^{(\mathrm{A})}}^{*}=\frac{K_{\mathrm{CO}_{2}{ }^{(\mathrm{A})}} K_{\mathrm{H}_{2}{ }^{(\mathrm{B})}}^{1 / 2}}{K_{\mathrm{HCOO}^{(\mathrm{A}, \mathrm{B})}}}$

$K_{\mathrm{OH}^{(\mathrm{A})}}^{*}=\frac{K_{\mathrm{H}_{2} \mathrm{O}^{(\mathrm{A}, \mathrm{B})}}}{K_{\mathrm{H}_{2}{ }^{(\mathrm{B})}}^{1 / 2}}$

with the temperature dependence of rate and adsorption constants given by the Arrhenius (Eq. 12) and van't Hoff (Eq. 13) equation, respectively:

$k=k_{0} \cdot \mathrm{e}^{-\frac{E_{\mathrm{A}}}{R T}}$

$K=K_{0} \cdot \mathrm{e}^{-\frac{\Delta H_{\text {ads }}}{R T}}$

Eq. 7 predicts a SRM reaction rate which is mainly determined by the methanol partial pressure. For water the rate shows a weak reverse dependence, expressed by a negative reaction order in a power law approach. The adsorption of carbon dioxide is competitive to that of methanol, water and the oxygenate intermediates and thereby inhibits the overall reaction. Moreover, water and methanol adsorption occurs dissociatively in combination with dehydrogenation, which should lead to strong inhibition by hydrogen. These predictions from the mechanistic rate law were compared with the experimental data.

Since the kinetic measurements were conducted under isothermal conditions at $220{ }^{\circ} \mathrm{C}$, values for activation energy $E_{\mathrm{A}}$ and heat of adsorption $\Delta H_{\text {ads }}$ could not be determined, except an apparent activation energy for the overall rate as discussed in Section 3.5.

For each catalyst the rate constant as well as the adsorption constants of methanol, water, hydrogen, carbon dioxide and the equilibrium constant of formate formation on the surface given in Eq. 7 were fitted to a total set of approx. 150 experimental rate data, calculated in the low conversion regime from the ratio of methanol conversion and contact time. The multi parameter fit was optimized by the minimization of the mean square error (MMSE). The following rate and adsorption constants of SRM over the catalysts CZA, CZC and CS were determined (Tab. 5) at a reaction temperature of $220{ }^{\circ} \mathrm{C}$. Since CCF showed a catalytic behaviour particularly different from the other three catalysts and could not be fitted with the model described above, its modelling will be described later.

As can be seen from the confidence intervals the rate constant $k^{*}$ was determined with the highest accuracy, whereas the adsorption constants $K_{\mathrm{CH}_{3} \mathrm{O}^{(\mathrm{A})}}^{*}, K_{\mathrm{OH}^{(\mathrm{A})}}^{*}$ and $K_{\mathrm{H}_{2}}{ }^{(\mathrm{B})}$ could be fitted only with moderate exactness. Since $K_{\mathrm{CO}_{2}{ }^{(\mathrm{A})}}$ and $K_{\mathrm{HCOO}^{(\mathrm{A})}}^{*}$ affect each other in the prediction the surface inhibition caused by carbon dioxide, either by molecular adsorption or by formate formation, their values have a relatively low accuracy. This may also explain the difference in the ratio of $K_{\mathrm{HCOO}^{(\mathrm{A})}}^{*}$ and $K_{\mathrm{CO}_{2}{ }^{(\mathrm{A})}}$ regarding CZA on the one hand and CZC and CS on the other hand. Nevertheless the elimination of one of these constants resulted in a significant loss of fitting quality and so both of them were kept in the rate equation. However, the stability index $\mathrm{R}^{2}$ is between 0.95 and 1.0 for the three catalysts confirming the good agreement between experimental data and microkinetic model. For a better comparison of the rate constants and in order to get information about the intrinsic rate constants the $k^{*}$ values have to be referred to the number of active sites on the catalyst surface. These surface concentrations are of course dependant on the copper content of the samples, but certainly not linear functions due to agglomeration effects regarding higher copper contents. However, since the absolute number of active sites is still unknown, a relatively rough comparison of the reaction rates related to the copper content is given in Section 3.5. Compared to data already published in the literature, the fitted parameters $K_{\mathrm{CH}_{3} \mathrm{O}^{(\mathrm{A})}}^{*}$ and $K_{\mathrm{H}_{2}{ }^{(\mathrm{B})}}$ for CZA come closer to the corresponding constants Peppley et al. [9] determined than the adsorption constants Lee et al. [10] measured for their $\mathrm{Cu} / \mathrm{ZnO} / \mathrm{Al}_{2} \mathrm{O}_{3}$ catalysts. The combined adsorption constant $K_{\mathrm{HCOO}^{(\mathrm{A})}}^{*}$ is two orders of magnitude higher than the value published by Peppley et al. This discrepancy may be explained by the fact that they did not observe carbon dioxide inhibition of SRM over their commercial catalyst. Lee et al. also did not observe this kind of inhibition and included neither a formate nor a carbon dioxide adsorption term in their kinetic model which indicates that even among $\mathrm{Cu} / \mathrm{ZnO} / \mathrm{Al}_{2} \mathrm{O}_{3}$ systems the relation between different surface species can differ strongly. However, since we in our DRIFTS study did not observe a molecularly adsorbed $\mathrm{CO}_{2}$ species but an inhibiting influence of this product gas on the SRM reaction was definitely observed, we assume carbon dioxide adsorption via carbonate formation, in agreement with a recent study [27].

As mentioned above, the $\mathrm{Cu} / \mathrm{Cr}_{2} \mathrm{O}_{3} / \mathrm{Fe}_{2} \mathrm{O}_{3}$ catalyst CCF showed a different behaviour in SRM than the other three tested catalysts. The dependence of the rate on the feed composition indicated a rate determining step beyond methoxy dehydrogenation and including the participation of water or hydroxyl groups. This is shown in Fig. 9 for SRM over CZA and CCF applying a varied binary feed composition of water and methanol without addition of inert or product gases.

The important difference between the curve shape for $\mathrm{CCF}$ and that of the other three catalysts is the plateau of the SRM reaction rate from $40 \%$ up to $80 \%$ methanol in the binary feed and the following remarkable decrease. Due to this shape the reaction could not be fitted sufficiently with the mechanistic rate law Eq. 7. Against that the rate of SRM over CZA steadily increases with increasing methanol partial pressure up to $90 \%$ methanol in the feed, which exactly fits the general shape of this function. 
Table 5: Parameters of microkinetic modelling of SRM over supported copper-catalysts CZA, CZC and CS, given with confidence interval ( \pm $5 \%$ of the absolute rate value) and stability index $\mathrm{R}^{2}$.

\begin{tabular}{|c|c|c|c|c|c|}
\hline & CZA & $\mathrm{CZC}$ & CS & $\mathrm{K} 3-110[9]$ & Synctix 33-5 [10] \\
\hline$k^{*}\left[\right.$ bar s $\left.s^{-1}\right]$ & $0.537 \pm 0.008$ & $0.422 \pm 0.012$ & $0.0920 \pm 0.003$ & & \\
\hline 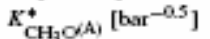 & $1.16 \pm 0.06$ & $0.86 \pm 0.06$ & $1.02 \pm 0.08$ & 0.862 & 4.93 \\
\hline$K_{\mathrm{OH}^{(\mathrm{A})}}^{+}\left[\mathrm{bar}^{-0.5}\right]$ & $0.06 \pm 0.01$ & $0.035 \pm 0.015$ & $0.033 \pm 0.017$ & 0.623 & - \\
\hline$K_{\mathrm{HCOCO}}^{(A)}\left[\mathrm{bar}^{-1.5}\right]$ & $17 \pm 4$ & $6.71 \pm 0.18$ & $7.4 \pm 0.6$ & 0.058 & - \\
\hline$K_{\mathrm{CO}_{2}^{(A)}\left[\mathrm{bar}^{-1}\right]}$ & $0.65 \pm 0.07$ & $7.2 \pm 0.6$ & $3.8 \pm 0.4$ & - & - \\
\hline$K_{\mathrm{H}_{2}}^{(\mathrm{Bi})}\left[\mathrm{bar}^{-1}\right]$ & $0.41 \pm 0.09$ & $0.77 \pm 0.02$ & $0.288 \pm 0.011$ & 1.16 & 12.6 \\
\hline
\end{tabular}

In the DRIFTS experiments it was shown that especially CCF was covered with a relatively high amount of formate groups. These results lead to the conclusion, that on this catalyst the formate dehydration is noticeably slower than on the other catalysts, maybe singularly rate determining, but definitely involved in the total rate. The mechanistic rate equation assuming formate dehydration (FDH) as the rate determining step in the catalysis cycle described in Fig. 7 is given by Eq. 14

$$
\begin{aligned}
& r \mathrm{FDH}=\left(k \mathrm{FDH} C_{\mathrm{S}_{\mathrm{A}}}^{\mathrm{T}}\left(C_{\mathrm{S}_{\mathrm{B}}}^{\mathrm{T}}\right)^{6} \prod_{i} K_{i}^{*}\left(p \mathrm{CH}_{3} \mathrm{OH} p \mathrm{H}_{2} \mathrm{O} / p_{\mathrm{H}_{2}}^{S / 2}\right)\right) \\
& /\left((1+\underbrace{K_{\left.\mathrm{CH}_{3} \mathrm{O}, \mathrm{A}\right)}^{+}\left(p \mathrm{CH}_{3} \mathrm{OH} / p_{\mathrm{H}_{2}}^{1 / 2}\right)}_{\text {methoxy }}\right. \\
& +\underbrace{K_{\mathrm{OH}^{(\mathrm{A})}}^{+}\left(p_{\mathrm{H}_{2} \mathrm{O}} / p_{\mathrm{H}_{2}}^{1 / 2}\right)}_{\text {bydroxy }}+\underbrace{\prod_{i} K_{i}^{*}\left(p_{\left.\mathrm{CH}_{3} \mathrm{OH} p_{\mathrm{H}_{2} \mathrm{O}} / p_{\mathrm{H}_{2}}^{5 / 2}\right)}\right.}_{\text {formate }} \\
& +\underbrace{K_{\mathrm{CO}_{2}^{(A)} p_{\mathrm{CO}_{2}}}}_{\text {carton dioxide }}) \times\left(1+K_{\mathrm{H}^{(\mathrm{B})}}^{1 / 2} p_{\mathrm{H}_{2}}^{1 / 2}\right)^{6}) \text {, }
\end{aligned}
$$

where $\prod_{i} K_{\mathrm{i}}^{*}$ represents the product of the equilibrium constants of all elemental reaction steps in the catalysis cycle from methanol adsorption up to dioxomethylene dehydrogenation (the rate law following the methyl formate route is the same with respect to its algebraic form but with different meaning of its parameters). Obviously this product of six factors prevents a meaningful fitting of experimental data and so the following discussion will only be qualitative. As can be seen, this rate law describes in the differential conversion regime $\left(p_{\mathrm{H}_{2}}, p_{\mathrm{CO}_{2}} \approx 0\right)$ a zero order reaction over a wide range of feed compositions. However, against the rate law with methoxy dehydrogenation as RDS this rate law predicts a decreasing rate with the decrease of water in the feed, which is exactly the observed result.

Applying Eq. 14 for fitting the rate data acquired from CCF could be better fitted than with Eq. 7, but still not in a sufficiently high quality. Since the experimental data, displayed in Fig. 7, seems to result from a combination of both fundamental rate equation shapes, a combined rate equation is proposed for the final description (Eq. 15)

$$
\frac{1}{r}=\frac{1}{r_{\mathrm{MDH}}}+\frac{1}{r_{\mathrm{FDH}}}
$$
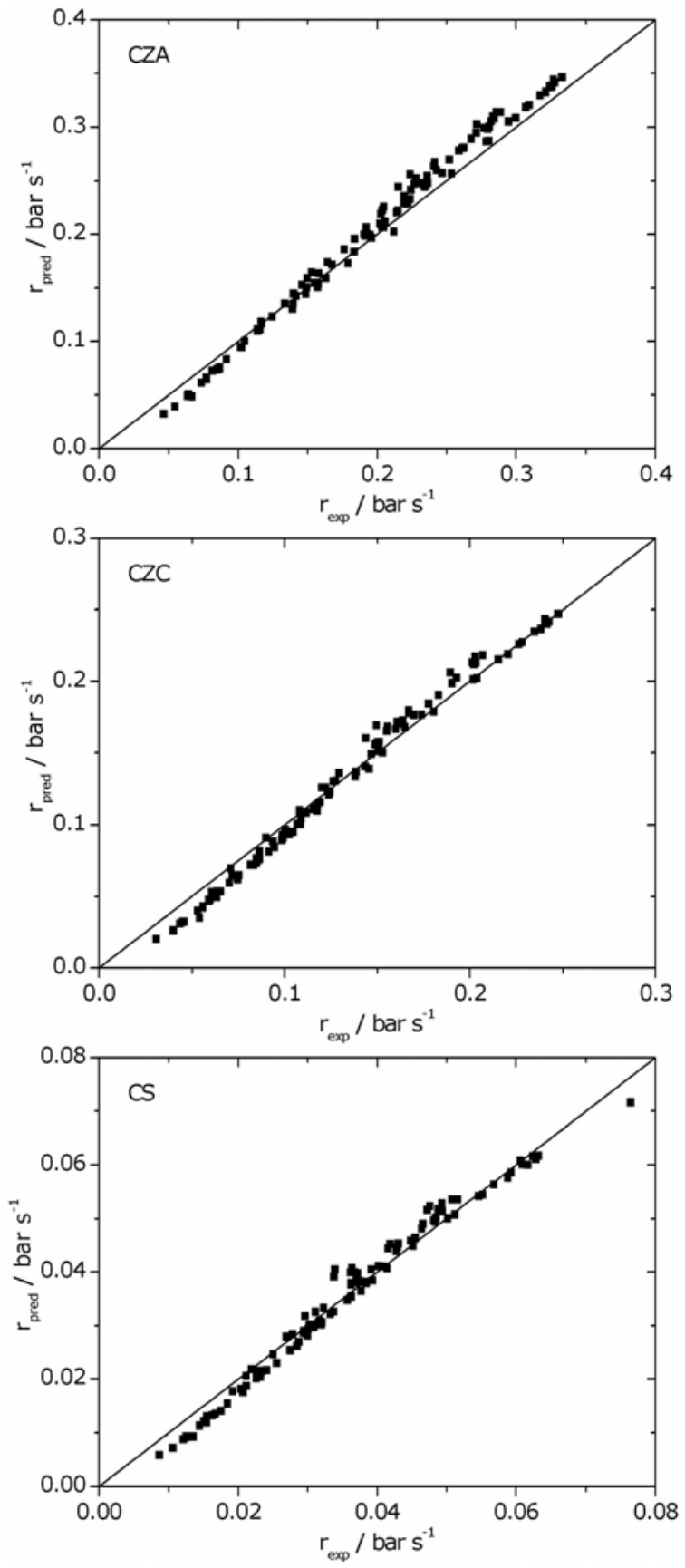

Figure 8: Parity plots of microkinetic modeling of SRM over $\mathrm{CZA}, \mathrm{CZC}$ and $\mathrm{CS}$.

which is the expression corresponding to Kirchhoff's law of electricity, implying that the total rate is mainly affected by the slowest of both elemental reactions, methoxy and formate dehydrogenation, whose activation barriers may be comparable to electronic resistors. Unfortunately only the 


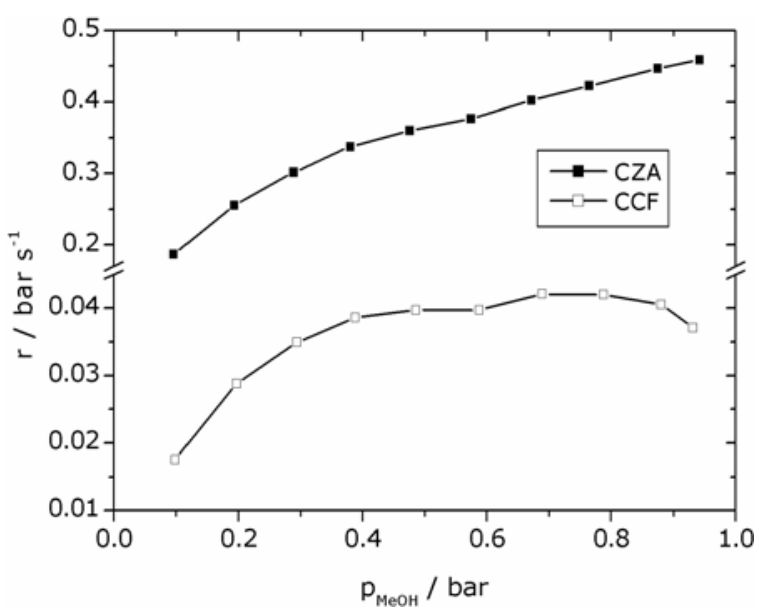

Figure 9: Comparison of the dependence of SRM reaction rate over CZA and CCF on the feed composition without addition of inert or product gases, $\mathrm{T}=220^{\circ} \mathrm{C}$.

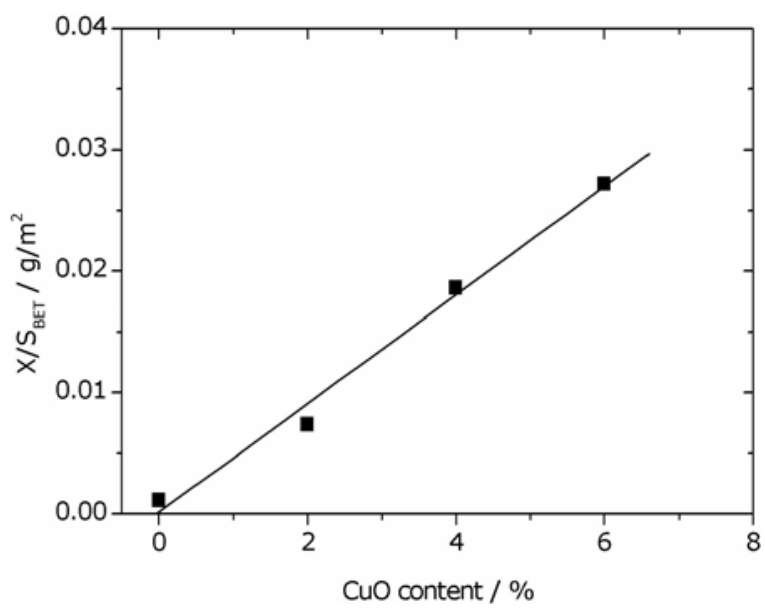

Figure 10: Dependence of the surface area related SRM activity of $\mathrm{CuO} / \mathrm{Cr}_{2} \mathrm{O}_{3} / \mathrm{Fe}_{2} \mathrm{O}_{3}$ catalyst samples from their copper oxide content.

general shape of the results can be explained using this model. The high reaction order of hydrogen in $r_{\mathrm{FDH}}$ predicts an immense inhibition of the reaction progress by its appearance, which is in this extent actually not observed in the experimental results. This results in unrealistically low values for the hydrogen adsorption constant $K_{\mathrm{H}^{(\mathrm{B})}}$ and thereby in high values for the product $\prod_{i} K_{\mathrm{i}}^{*}$, although the rate data fit reaches a sufficient accuracy. The values of the fitted parameters are not presented here. However, the assumption that SRM over CCF has a second barrier at the formate dehydrogenation is also confirmed by its low selectivity. Compared to the other three catalysts, CCF produced a high amount of $\mathrm{CO}$ in the product stream which must have formed from an intermediate preliminary to formate, since formate itself decomposes directly into the main reaction products $\mathrm{H}_{2}$ and $\mathrm{CO}_{2}$. Millar [45] and Fisher [46] reported the $\mathrm{CO}$ formation from methyl formate in the absence of water. Although not observed in the DRIFTS studies, the increased $\mathrm{CO}$ production may indicate a higher amount of methyl formate on the surface due to a slower formate dehydrogenation.

Due to these differences observed in the catalytic behaviour it was considered necessary to prove that the SRM catalysis over CCF involves copper as active phase, since $\mathrm{Fe}_{2} \mathrm{O}_{3} / \mathrm{Cr}_{2} \mathrm{O}_{3}$ systems are known to be active for water-gas shift catalysis and a certain activity in methanol steam reforming may be considered possible. In order to show the activity as a function of the copper content, catalyst samples with different compositions were synthesized. The ratio of $\mathrm{Cr}_{2} \mathrm{O}_{3}$ and $\mathrm{Fe}_{2} \mathrm{O}_{3}$ was kept constant at the value given by $\mathrm{CCF}$ whereas the copper content was varied from 0 to $6 \%$. The activity in SRM was determined at $300{ }^{\circ} \mathrm{C}$ and an equimolar methanol/water feed of $0.5 \mathrm{ml} \mathrm{min}^{-1}$. The observed conversions were related to the BET surface areas of the samples. A linear correlation of this modified activity and the copper content of the sample was expected from Eq. 8 and observed as shown in Fig. 10.

This result is a clear indication that copper or a copper containing phase formed in these samples is responsible for the catalytic activity. Since the copper-free sample provides nearly no activity, the contribution of the $\mathrm{Fe}_{2} \mathrm{O}_{3} / \mathrm{Cr}_{2} \mathrm{O}_{3}$ catalyst support to the measured conversion can be neglected. The linear increase in this lowconcentration range indicates the formation of uniform and unisized copper particles.

In an early stage of this study it was observed that the $\mathrm{Cu} / \mathrm{Cr}_{2} \mathrm{O}_{3} / \mathrm{Fe}_{2} \mathrm{O}_{3}$ high temperature shift catalyst exhibits remarkably low activity and poor selectivity for methanol steam reforming, and this combination will definitely never reach technical application for this reaction. However, this catalyst was not suspended from further experiments since there is a pool of information about a reaction system that cannot be discovered by the analysis and investigation of good and optimized catalysts. The knowledge of reasons why particular systems, e.g. CCF as a catalyst for SRM, do not operate in the supposed way sometimes gives deeper insight and better understanding of the well working systems.

Vargas et al. in their recent study [27] proposed the methanol adsorption during SRM to occur on oxidized surface sites independent of the presence of oxygen in the feed. They proposed that these sites in the absence of oxygen are formed via dissociative water adsorption, especially at low temperatures $\left(<250^{\circ} \mathrm{C}\right)$. A kinetic evaluation of this pathway should result inevitably in a much stronger impact of water concentration on the SRM reaction rate than it was actually found in our study. From the kinetic point of view this mechanism could not be adapted to our experimental results. However, their DRIFTS study was conducted at even higher temperatures up to $450{ }^{\circ} \mathrm{C}$. Despite of these contradiction they also identified the selectivity determining step between methoxy and formate intermediates, which is in agreement with our results. Enhanced CO formation via formate decomposition [27] as well as via methyl formate decomposition $[45,46]$ match well with the higher amount of formate groups on $\mathrm{CCF}$ and the resulting poor selectivity towards $\mathrm{CO}_{2}$. Indeed a recent kinetic study on the SRM reaction network over CCF (B. Frank, unpub 
Table 6: Rate constants and reaction orders of SRM over the investigated copper-containing catalysts measured at $220^{\circ} \mathrm{C}$.

\begin{tabular}{|c|c|c|c|c|c|c|c|}
\hline Catalyst & $k\left[\operatorname{bar}^{x} s^{-1}\right]$ & $n_{\mathrm{M}}$ & $n_{w}$ & $n_{\mathrm{H}}$ & $n_{\mathrm{C}}$ & $n_{\mathrm{N}}$ & $R^{2}$ \\
\hline$\overline{C Z A}$ & $0.117 \pm 0.004$ & $0.491 \pm 0.012$ & $0.021 \pm 0.008$ & $-0.31 \pm 0.01$ & $-0.082 \pm 0.005$ & $-0.021 \pm 0.008$ & 0.963 \\
\hline $\mathrm{CCF}$ & 0.034 & 0.52 & 0.11 & -0.19 & -0.09 & -0.01 & \\
\hline $\mathrm{CZC}$ & $0.062 \pm 0.002$ & $0.603 \pm 0.010$ & $0.032 \pm 0.006$ & $-0.319 \pm 0.007$ & $-0.173 \pm 0.005$ & $0.017 \pm 0.005$ & 0.979 \\
\hline
\end{tabular}

lished results) indicated that $\mathrm{CO}$ formation over this catalyst mainly occurs via methanol decomposition, whereas the main source of CO over CZA and CZC was shown to be the reverse water-gas shift reaction $[5,8]$.

\subsubsection{Power law fit}

Because of their easier handling power rate laws are very often used for sizing of reactors in industrial and technical sciences [47-49]. An interesting difference among several power rate laws given in the literature is found in the inhibiting effect of carbon dioxide. Jiang et al. [32] and Lee et al. [10] could not measure any inhibition of carbon dioxide on $\mathrm{SRM}$ over $\mathrm{Cu} / \mathrm{ZnO} / \mathrm{Al}_{2} \mathrm{O}_{3}$ catalysts. In contrast, Idem et al. [50] and Samms et al. [51] indeed found such a inhibition over their copper-catalysts. For technical application this differentiation between two inhibiting species is of no importance since hydrogen and carbon dioxide are formed in the strict stochiometric ratio of 3 and their exponents thereby can be transformed algebraically. But from a mechanistic point of view this finding may be very important as shown above.

Since many kinetic studies found in the literature are based on simple power rate laws, we completed our investigation with a power law fit of the kinetic data in order to allow a better comparison with the results of research groups, who only published power law fits. The reaction orders of methanol $n_{\mathrm{M}}$, water $n_{\mathrm{W}}$, hydrogen $n_{\mathrm{H}}$ and carbon dioxide $n_{\mathrm{C}}$ were fitted to the complete dataset of about 200 data points for each catalyst with a rate expression of the following form (Eq. 16)

$r=k \cdot p_{\mathrm{CH}_{3} \mathrm{OH}}^{\mathrm{n}_{\mathrm{M}}} \cdot p_{\mathrm{H}_{2} \mathrm{O}}^{\mathrm{n}_{\mathrm{W}}} \cdot p_{\mathrm{H}_{2}}^{\mathrm{n}_{\mathrm{H}}} \cdot p_{\mathrm{CO}_{2}}^{\mathrm{n}_{\mathrm{C}}}$

where $r$ is the reaction rate of methanol consumption (bar s$\left.{ }^{1}\right), k$ the rate constant $\left(\operatorname{bar}^{\mathrm{x}} \mathrm{s}^{-1}\right.$ with $\mathrm{x}=1-\Sigma n_{\mathrm{i}}$ ), $p_{\mathrm{i}}$ the partial pressures (bar) and $n_{\mathrm{i}}$ the reaction orders of the reactants.

As expected from the mechanistic modelling we found the reaction rate to be mainly determined by the methanol partial pressure, whereas the reaction order of water is very low for all catalysts. Both main reaction products were found to inhibit the reaction which is expressed in negative reaction orders. The reaction order of nitrogen $n_{\mathrm{N}}$ was found to be $0 \pm 0.02$ as expected and the range of \pm 0.02 may indicate the experimental error of our investigation. The results of the power law fit are assembled in Tab. 6.

Lee et al. [10] used a power expression for hydrogen of the type $\left(\mathrm{A}+p_{\mathrm{H}_{2}}\right)^{n_{\mathrm{H}}}$ in order to undergo infinite reaction rates at the reactor inlet, where the partial pressure of hydrogen is zero. For numerical fitting we solved this mathematical problem by initialising the hydrogen partial pressure with an extremely small value of $10^{-5}$ bar. Indeed the variation of this initialization parameter in the range of $10^{-4}-10^{-7}$ bar causes a negligible deviation of the predicted methanol conversion of $<0.1 \%$.

As can be seen from Tab. 6, the reaction order of water is the highest on CCF. This is in good agreement with the results of the mechanistic study because on this catalyst the influence of the water partial pressure is relatively high due to the influence of formate dehydrogenation on the overall reaction rate. The water reaction orders are slightly positive on CZA, CZC and CS against the slightly negative reaction order which the pure application of Eq. 7 predicts. Possibly this also indicates a small influence of formate dehydrogenation on the SRM reaction rate on these catalysts.

\subsection{Apparent activation energy and comparison of activity}

From the temperature dependence of the reaction rate, the apparent activation energy was calculated from the slope of the dataset in an Arrhenius plot (Fig. 11). Linearity was observed for each catalyst indicating that there is no change in the rate determining step or diffusion limitation in the investigated temperature range. The diagram also gives a clear comparison of the activities of the catalysts.

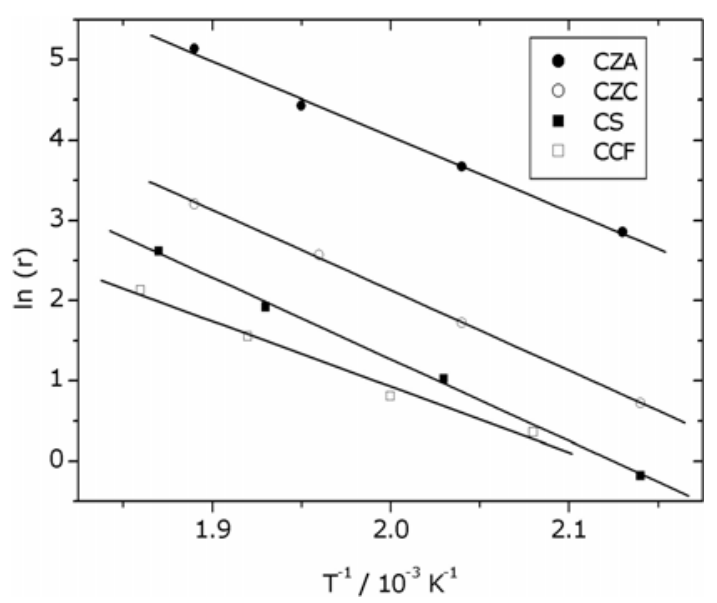

Figure 11: Arrhenius plot for SRM over the investigated coppercatalysts in the temperature range of $200-250{ }^{\circ} \mathrm{C}\left(m_{\mathrm{CZA}}=0.5 \mathrm{~g}\right.$, $m_{\mathrm{CCF}}=2.5 \mathrm{~g}, m_{\mathrm{CZC}}=1.0 \mathrm{~g}, m_{\mathrm{CS}}=2.0 \mathrm{~g}, p=1 \mathrm{bar}, w=0.3-2 \mathrm{ml}$ $\min ^{-1}, \mathrm{MeOH} / \mathrm{H}_{2} \mathrm{O}=1$, reaction rate $r$ in mmol s $\mathrm{kg}^{-1}$ ). 
Table 7: Activation energies and reaction rates at $220{ }^{\circ} \mathrm{C}$ of copper-based catalysts expressed for overall catalyst amount and $\mathrm{Cu}$ content.

\begin{tabular}{llll}
\hline Sample & $E_{\mathrm{A}}\left[\mathrm{kJ} \mathrm{mol}{ }^{-1}\right]$ & $r_{220}\left[\mathrm{mmol} \mathrm{kg}_{\mathrm{Cat}^{5}}^{-1}{ }^{-1}\right]$ & $r_{220}\left[\mathrm{mmol} \mathrm{kg}_{\left.\mathrm{Cu}^{-1} \mathrm{~s}^{-1}\right]}\right.$ \\
\hline CZA & 76.9 & 44.1 & 80.3 \\
CCF & 67.4 & 2.0 & 100.2 \\
CZC & 84.9 & 6.4 & 92.2 \\
$\mathrm{CS}$ & 85.7 & 2.6 & 22.5 \\
\hline
\end{tabular}

The activation energies $E_{A}$ determined from the Arrhenius plot and the reaction rate at $220{ }^{\circ} \mathrm{C}$ are assembled in Tab. 7.

The activation energies of SRM over CZC and CS are nearly identical, which is in agreement with our assumption of the same RDS. The temperature dependence over CZA is a little lower, but this can be attributed to the high copper content of this sample as shown in a previous study [5]. A clear difference in the activation energy is observed for $\mathrm{CCF}$, this value is noticeably low, indicating a difference in the RDS as described in detail above. An extremely low value of $E_{\mathrm{A}}$ for SRM over a $\mathrm{Cu} / \mathrm{Cr}_{2} \mathrm{O}_{3} / \mathrm{Fe}_{2} \mathrm{O}_{3}$ water-gas shift catalyst was also found by Löffler et al. [52].

Since there are no comparable data on the influence of the catalyst support on the activity in SRM we compared the activities referred to the mass of copper with specific activities found for methanol synthesis given by Fujitani et al. [53]. They have found that the specific activity of copper-based catalysts depends on the support in the decreasing order $\mathrm{Cr}_{2} \mathrm{O}_{3}>\mathrm{ZrO}_{2} \approx \mathrm{Al}_{2} \mathrm{O}_{3}>\mathrm{SiO}_{2}$ and observed a promoting effect of $\mathrm{ZnO}$ on each support. Taking into account that our $\mathrm{Cu} / \mathrm{ZnO} / \mathrm{Al}_{2} \mathrm{O}_{3}$ catalyst was up to 5 times less active than other systems reported (see Section 3.1), these results are in good agreement. Although there are of course remarkable differences in the copper loading of our catalysts and the influence of $\mathrm{Fe}_{2} \mathrm{O}_{3}$ and $\mathrm{CeO}_{2}$ was neglected in this comparison, this may be an indication for the similarity of the active sites of copper-based catalysts used in methanol synthesis and steam reforming of methanol.

\section{Conclusion}

The reaction mechanism of methanol steam reforming was investigated in detail by means of a kinetic study based on the differential method. The proposed reaction mechanism, based on previous studies, was supported by a DRIFTS study. Microkinetic measurements were conducted, taking thoroughly care of the elimination of mass transfer limitation as well as experimental errors and result falsification due to catalyst aging.

The elementary reaction steps occurring on the surfaces of copper catalysts during steam reforming of methanol were found to be similar and independent of the catalyst support. As reported by several authors, the dehydrogenation of methoxy groups was found to be the rate determin- ing step of this reaction over $\mathrm{Cu} / \mathrm{ZnO} / \mathrm{Al}_{2} \mathrm{O}_{3}$ catalysts. This insight was extended to $\mathrm{Cu} / \mathrm{SiO}_{2}$ and $\mathrm{Cu} / \mathrm{ZrO}_{2} / \mathrm{CeO}_{2}$ systems, which showed identical reaction rate dependence on the feed composition. Kinetic constants were found to be in the same order of magnitude for each catalyst. The surfaces of all catalysts were dominated by methoxy and formate groups, the intermediates formaldehyde, dioxomethylene and methyl formate could not be observed. Since methyl formate appears in the product spectrum only at high methanol surplus, a change in the reaction pathway is supposed from the dioxomethylene to the methyl formate route, depending on the water content in the feed. A strong signal of formate groups in the DRIFTS spectrum indicates a relatively slow decomposition of these species into the reaction products. This does not affect the reaction rate over the investigated $\mathrm{Cu} / \mathrm{ZnO} / \mathrm{Al}_{2} \mathrm{O}_{3}, \mathrm{Cu} / \mathrm{SiO}_{2}$ and $\mathrm{Cu} / \mathrm{ZrO}_{2} / \mathrm{CeO}_{2}$ catalysts. Regarding the $\mathrm{Cu} / \mathrm{Cr}_{2} \mathrm{O}_{3} / \mathrm{Fe}_{2} \mathrm{O}_{3}$ catalyst, this step was indeed found to decrease the overall reaction rate and a combined rate was proposed considering methoxy and formate dehydrogenation as the two slowest elementary reaction steps. This noticeable result was confirmed by a thorough evaluation of the corresponding band areas in the DRIFTS spectra as well as by a higher formation of the by-product $\mathrm{CO}$ over this catalyst, which is probably formed by the decomposition of methyl formate, the surface intermediate preliminary to formate in the supposed catalysis cycle. A particular low apparent SRM activation energy over CCF compared to CZA, CZC and CS also confirms the assumption of a change in the rate determining step on this catalyst.

\section{Acknowledgement}

Financial support by the ZEIT-foundation (project "Nanochemistry for the automobiles of the future", http://www.zeit-stiftung.de) is gratefully acknowledged. The authors further wish to thank Dr. Ágnes Mastalir (University of Szeged, Hungary) for helpful discussions. 


\section{References and Notes}

[1] A. Chambers, C. Park, R.T.K. Baker, N.M. Rodriguez, J. Phys. Chem. B. 102 (1998) 4253.

[2] [B. Lindström, L.J. Petterson, Int. J. Hydrogen Energy 26 (2001) 923.

[3] G. Jacobs, B.H. Davis, Appl. Catal. A, 285 (2005) 43.

[4] G.A. Olah, Catal. Lett. 93 (2004) 1.

[5] A. Mastalir, B. Frank, A. Szizybalski, H. Soerijanto, A. Deshpande, M. Niederberger, R. Schomäcker, R. Schlögl, T. Ressler, J. Catal. 230 (2005) 464.

[6] B.A. Peppley, J.C. Amphlett, L.M. Kearns, R.F. Mann, Appl. Catal. A 179 (1999) 21.

[7] B. Lindström, L. Petterson, J. Power Sources 118 (2003) 71.

[8] H. Purnama, T. Ressler, R.E. Jentoft, H. Soerijanto, R. Schlögl, R. Schomäcker, Appl. Catal. A 259 (2004) 83.

[9] B.A. Peppley, J.C. Amphlett, L.M. Kearns, R.F. Mann, Appl. Catal. A 179 (1999) 31.

[10] J.K. Lee, J.B. Ko, D.H. Kim, Appl. Catal. A 278 (2004) 25.

[11] S.A. Asprey, B.W. Wojciechowski, B.A. Peppley, Appl. Catal. A 179 (1999) 51.

[12] M.P. Harold, B. Nair, G. Kolios, Chem. Eng. J. 58 (2003) 2551.

[13] A. Morillo, A. Freund, C. Merten, Ind. Eng. Chem. Res. 43 (2004) 4624.

[14] F. Gallucci, L. Paturzo, A. Basile, Ind. Eng. Chem. Res. 43 (2004) 2420.

[15] C.J. Jiang, D.L. Trimm, M.S. Wainwright, N.W. Cant, Appl. Catal. A 97 (1993) 145.

[16] K. Takahashi, N. Takezawa, H. Kobayashi, Appl. Catal. 2 (1982) 363

[17] Y. Choi, H.G. Stenger, Appl. Catal. B 38 (2002) 259.

[18] Y. Liu, T. Hayakawa, K. Suzuki, S. Hamakawa, T. Tsunoda, T. Ishii, M. Kumagai, Appl. Catal. A 223 (2002) 137.

[19] N. Takezawa, N. Iwasa, Catal. Today 36 (1997) 45.

[20] K. Takahashi, N. Takezawa, H. Kobayashi, Chem. Lett. (1985) 759 (cited in [18])

[21] J. Skrzypek, J. Sloczynki, S. Ledakowicz, Methanol Synthesis, ISBN 83-01-11490-8, Polish Scientific Publishers, Warsaw, 1994 (cited in [26]).

[22] R.J. Burch, S.E. Golunski, M.S. Spencer, Catal. Lett. 5 (1990) 55.

[23] K.D. Jung, A.T. Bell, J. Catal. 193 (2000) 207.

[24] J. Agrell, H. Birgersson, M. Boutonnet, I. Melián-Cabrera, R.M. Navarro, J.L.G. Fierro, J. Catal. 219 (2003) 389.

[25] J.P. Breen, F.C. Meunier, J.R.H. Ross, Chem. Commun. (1999) 2247.

[26] P.H. Matter, U.S. Ozkan, J. Catal. 234 (2005) 463.

[27] M.A.L. Vargas, G. Busca, U. Costantino, F. Marmottini, T. Montanari, P. Patrono, F. Pinzari, G. Ramis, J. Mol. Catal. A
(2006), doi:10.1016/j.molcata.2006.08.085

[28] G. Jacobs, B.H. Davis, Appl. Catal. A 285 (2005) 43.

[29] A.S. Deshpande, N. Pinna, P. Beato, M. Antonietti, M. Niederberger, Chem. Mater. 16 (2004) 2599.

[30] L. Trouillet, T. Toupance, F. Villain, C. Louis, Phys. Chem. Chem. Phys. 2 (2000) 2005.

[31] J.M. Coulson, J.F. Richardson, R.K. Sinnott, Chemical Engineering Vol. 6, Pergamon Press, Oxford, 1983, p. 253.

[32] C.J. Jiang, D.L. Trimm, M.S. Wainwright, N.W. Cant, Appl. Catal. A 93 (1993) 245.

[33] M. Baerns, H. Hofmann, A. Renken, Chemische Reaktionstechnik, third ed., Georg Thieme Verlag, Stuttgart, 1999 (german)

[34] J.R. Katzer, Dissertation, Massachusetts Institute of Technology, Cambridge, Massachusetts, 1969 (cited in [4]).

[35] M. Kurtz, H. Wilmer, T. Genger, O. Hinrichsen, M. Muhler, Catal. Lett. 86 (2003) 77.

[36] M.V. Twigg, M.S. Spencer, Top. Catal. 22 (2003) 191.

[37] X. Zhang, P. Shi, J. Mol. Catal. A 194 (2003) 99.

[38] A. Szizybalski, F. Girgsdies, A. Rabis, Y. Wang, M. Niederberger, T. Ressler, J. Catal., 233 (2005) 297.

[39] V. Agarwal, S. Patel, K.K. Pant, Appl. Catal. A 279 (2005) 155.

[40] D.B. Clarke, D.K. Lee, M.J. Sandoval, A.T. Bell, J. Catal. 150 (1994) 81.

[41] D.M. Monti, N.W. Cant, D.L. Trimm, M.S. Wainwright, J. Catal. 100 (1986) 17.

[42] R. Zhang, Y. Sun, S. Peng, Fuel 11-12 (2002) 1619.

[43] G.J. Millar, C.H. Rochester, K.C. Waugh, J. Chem. Soc. Faraday Trans. 87 (1991) 2795.

[44] G. Busca, A.S. Elmi, P. Fortazzi, J. Phys. Chem. 91 (1987) 5263.

[45] G.J. Millar, C.H. Rochester, K.C. Waugh, J. Chem. Soc., Farad. Trans. 87 (1991) 2795.

[46] I.A. Fisher, A.T. Bell, J. Catal. 184 (1999) 357.

[47] J. Agrell, H. Birgersson, M. Boutonnet, J. Power Sources 4654 (2002) 1.

[48] P. Reuse, A. Renken, K. Haas-Santo, O. Görke, K. Schubert, Chem. Eng. J. 102 (2004) 133.

[49] L. Ma, C. Jiang, A.A. Adesina, D.L. Trimm, M.S. Wainwright, Chem. Eng. J. 62 (1996) 103.

[50] R.O. Idem, N.N. Bakhshi, Chem. Eng. Sci. 51 (1996) 3697.

[51] S.R. Samms, R.F. Savinell, J. Power Sources 112 (2002) 13.

[52] D.G. Löffler, S.D. McDermott, C.N. Renn, J. Power Sources 114 (2003) 15.

[53] T. Fujitani, M. Saito, Y. Kanai, T. Kakumoto, T. Watanabe, J. Nakamura, T. Uchijima, Catal. Lett. 25 (1994) 271.

[54] C.T. Wang, R.J. Willey, J. Catal. 202 (2001) 211. 